\title{
INTELLIGENCE PROMOTES COOPERATION IN LONG-TERM INTERACTION: EXPERIMENTAL EVIDENCE IN INFINITELY REPEATED PUBLIC GOODS GAMES
}

\author{
Tetsuya Kawamura \\ Tiffany Tsz Kwan Tse
}

October 2021

The Institute of Social and Economic Research

Osaka University

6-1 Mihogaoka, Ibaraki, Osaka 567-0047, Japan 


\title{
Intelligence promotes cooperation in long-term interaction: Experimental evidence in infinitely repeated public goods games
}

\author{
Tetsuya Kawamura ${ }^{1}$ and Tiffany Tsz Kwan Tse ${ }^{2^{*}}$ \\ $1^{*}$ Department of Economics, Tezukayama University, \\ Tezukayama, Nara, 6318501, Japan. \\ ${ }^{2}$ Institute of Social and Economic Research, Osaka University, \\ Ibaraki, Osaka, 5670047, Japan.
}

*Corresponding author(s). E-mail(s): tiffany.ttk@gmail.com; Contributing authors: kawamuratetsuya2027@gmail.com;

\begin{abstract}
A growing body of literature in experimental economics examines how cognitive ability affects cooperation in social dilemma settings. We contribute to the existing literature by studying this relationship in a more complex and strategic environment when the number of partners increases in an infinitely repeated public goods game. We designed four treatments with different continuation probability under two conditions: whether cooperation can be sustained as risk dominance or not. We asked participants to decide whether to cooperate in every period in the first five rounds. They were further asked to decide if they should elicit their strategy at the beginning of each super game using the strategy method in the last five rounds. We found that participants with greater cognitive abilities cooperated more (less) when cooperation could(not) be sustained as risk dominance. A similar trend was observed in the frequency of fully cooperative strategies. We also found that participants with greater cognitive abilities employed lenient and forgiving strategies more frequently when the continuation probability was far higher than the risk dominant threshold level.
\end{abstract}

Keywords: cognitive ability, infinitely repeated game, public goods game, risk dominance, strategy method

JEL Classification: C72, C73 , C91 , C92 


\section{Introduction}

How does the intelligence of participants affect decision-making in strategic interactions? It may depend on the number of equilibria of the game and whether the interaction is intertemporal. Experimental evidence (see BrañasGarza et al. (2012), Carpenter et al. (2013), and Gill and Prowse (2016) for p-beauty game experiments; Kawamura and Ogawa (2019) for recipient behavior in ultimatum game experiments; and Barreda-Tarrazona et al. (2017) for prisoner's dilemma (PD) game experiments) suggests that more intelligent individuals will exhibit behavior close to the theoretical prediction in the one-shot game, with a single sub-game perfect Nash equilibrium (SPE).

When a game is repeated and the strategic interaction is intertemporal, even if the game has a unique SPE, the relationship between intelligence and behavior is complicated. Al-Ubaydli et al. (2016) and Barreda-Tarrazona et al. (2017) found no significant relationship between participants' intelligence and cooperation rates in finitely repeated $\mathrm{PD}$ game experiments.

When the game has multiple SPEs, the relationship between participants' intelligence and behavior becomes more complicated. Jones (2008) found a positive relationship between participants' intelligence and cooperation rate. Proto et al. (2019) established that intelligence has a large and positive longrun effect on cooperative behavior in an infinitely repeated $\mathrm{PD}$ game.

Can the same trend of more intelligent individuals becoming more cooperative in long-term interactions in a more complex strategic environment be achieved when the number of partners increases in an infinitely repeated public goods (PG) game? This study is an attempt to answer this question.

The rich experimental literature on infinitely repeated PD games provides important attributes for studying infinitely repeated PG games. These studies investigate cooperative behavior in infinitely repeated PD games from the following aspects: equilibrium selection (Blonski et al., 2011), the shadow of the future (Dal Bó \& Fréchette, 2011), strategy methods (Dal Bó \& Fréchette, 2019; Romero \& Rosokha, 2018), discounting and random termination (Fréchette \& Sevgi, 2017), and the effects of intelligence and personal characteristics (Dreber et al., 2014; Proto et al., 2019). ${ }^{1}$

Dal Bó and Fréchette (2011) found that increasing the continuation probability $\delta$ facilitates cooperation. Blonski et al. (2011) established that when the grim trigger strategy (GRIM) ${ }^{2}$ is supported as a risk dominance equilibrium (RDE), cooperation is more easily achieved than when it is not an RDE. Proto et al. (2019) found that participants with high cognitive ability cooperate or employ cooperative strategies more frequently when GRIM is an RDE.

Few experimental studies have investigated infinitely repeated PG games, as most compare cooperative behavior in infinitely and finitely repeated games. Palfrey and Rosenthal (1994) determined that the cooperation rate is higher in an infinitely repeated PG game than in a one-shot PG game. Tan and Wei

\footnotetext{
${ }^{1}$ In addition, some studies have examined the impact of monitoring (Aoyagi et al., 2019) and group matching methods (Duffy \& Ochs, 2009) in infinitely repeated PD games.

${ }^{2}$ Players using GRIM will cooperate if all partners cooperate; otherwise, they defect.
} 
(2014) found no significant difference in the cooperation rate between finitely and infinitely repeated PG games. Lugovsky et al. (2017) established that the cooperation rate is significantly higher in infinitely repeated settings than in finitely repeated settings in a four-person PG game. Sell and Wilson (1999) compared the cooperation rate under multiple $\delta$ in infinitely repeated PG games and found that the cooperation rate increases when $\delta$ increases, but only in the treatment in which participants are required to employ the grim trigger strategy. They designed treatments in which GRIM is supported as an SPE, but not as an RDE. To our knowledge, no study has explored cooperative behavior when GRIM is supported as an RDE in infinitely repeated PG games.

The threshold discount factor for RDE is known to be a good predictor of the cooperation trend in infinitely repeated PD game experiments. This study examined whether higher intelligence allows for more efficient equilibria to be reached by processing richer information. The theoretical prediction from twoperson games was extended to n-person games (Carlsson \& van Damme, 1993; Kim, 1996 $)^{3}$ to design $\delta$, so that we have one treatment for which $\delta$ is lower than the risk-dominant threshold and two treatments for which $\delta$ is higher than the risk-dominant threshold.

In an infinitely repeated PG game, the strategy space is broader than in an infinitely repeated PD game. Unlike the PD game, punishing a player who deviates from the equilibrium strategy in the PG game not only affects the payoff of the punished player, but also affects the payoff of the other players who did not deviate from the equilibrium strategy. To achieve mutual cooperation, participants have more chances to employ lenient and forgiving strategies. To our knowledge, no existing study has explored strategies in an infinitely repeated PG game. By employing the one-period-ahead strategy method presented in Dal Bó and Fréchette (2019)'s study , we explored the strategy in an infinitely repeated PG game. We investigated not only the difference in cooperation rate, but also the difference in strategies between participants with high cognitive ability (HCA) and participants with low cognitive ability (LCA).

The remainder of this paper is organized as follows. In Section 2, we introduce the experimental design and procedure. In Section 3, we introduce the methodology employed. In Section 4, we propose our hypotheses based on the two equilibrium concepts in infinitely repeated game theory: the SPE and RDE. In Section 5, we present our experimental results. In Sections 6 and 7 , we discuss our findings and conclude the paper, respectively.

\section{Experimental Design}

\subsection{Parameter settings}

The group comprised of four players who played the PG game infinitely and repeatedly. In the $\mathrm{PG}$ game, players make a binary choice regarding whether to cooperate or not. We set the initial endowment to 10, and the marginal

\footnotetext{
${ }^{3}$ Carlsson \& van Damme (1993) and Kim (1996) explore Harsanyi and Selten (1988)'s notion of RDE in two-person to n-person games.
} 
per capita return at 0.5 . Here, $x_{i}$ denotes player $i$ 's level of cooperation. The payoff of player $i$ is given by:

$$
\pi_{i}=10-x_{i}+0.5 \sum_{j=1}^{4} x_{j}
$$

We set the continuation probability of all treatments above the threshold level in which GRIM is supported as an SPE. Therefore, we focused on situations where both cooperative and non-cooperative equilibria exist in all treatments. In an infinitely repeated PD game, whether GRIM is supported as an RDE or not can be a good predictor of the cooperation trend, as in the infinitely repeated PD game experiments. We investigated cooperative behavior when GRIM is and is not supported as an RDE.

We conducted four treatments with $\delta_{T 1}=0.4$ (Treatment 1 , or T1), $\delta_{T 2}=$ $0.6(\mathrm{~T} 2), \delta_{T 3}=0.8(\mathrm{~T} 3)$, and $\delta_{T 4}=0.9$ (T4), where GRIM is supported as the SPE in all the treatments and is supported as an RDE in T3 and T4. The threshold value of the continuation probability for GRIM to be supported as $\operatorname{RDE} \delta_{R D E}$ is 0.8 , which is equal to $\delta_{T 3}{ }^{4}$. We set $\delta_{T 1}$ and $\delta_{T 2}$ to be lower than $\delta_{R D E}$, and $\delta_{T 4}$ was higher than $\delta_{R D E}$.

\subsection{Experimental Procedure}

The experiments were conducted in the laboratory of the Center for Experimental Economics at Kansai University. We used the online bulletin board of Kansai University to recruit participants who did not have any experience with PG and PD game experiments. Experiments were conducted in eleven sessions between July 2018 and July 2021. Each participant participated in only one session.

Each session lasted about 120 (180) min in T1, T2 and T3 (T4) and was conducted by the same experimenter. After the participants were randomly assigned to their seats, they were asked to sign the consent form. After confirming that all participants had signed the consent form, the experimenter read them the instructions. Each participant received printed handouts of the instructions and listened to the audio instructions. During this time the participants could ask any questions about the experiment. After the instructions, a three-question review test about the payoff calculation was conducted to check the participants' understanding of the game. After all the participants had answered every question correctly, the experiment began.

The experiment was implemented using a z-tree (Fischbacher, 2007). Each session consisted of 10 rounds (also called supergames), and in each round, participants repeatedly played a PG game with their fixed partners. The number of periods in a round is determined by the $\delta$ of the corresponding treatment (0.4 in T1, 0.6 in T2, 0.8 in T3, and 0.9 in T4, respectively). At the end of each period, the experimenter drew one card from five cards, which consisted

\footnotetext{
${ }^{4}$ The procedure for calculating the threshold value of continuation probability for GRIM to be supported as an RDE is shown in the Appendix A.
} 
of three jokers (two jokers) [one joker] and two (three) [four] spade cards in T1 (T2) [T3]. The experimenter drew one card from 10 cards, which consisted of one joker and nine spade cards in T4. When the experimenter drew a joker, the round was finished, all members were randomly re-matched, and the next round started with four new members. The process of drawing cards was shown on the screen at the front of the laboratory. Therefore, it was ensured that the continuation of every period by the given probability is common knowledge.

The decision-making methods in the first five rounds and the last five rounds differed. Participants decide whether to cooperate in every period in the first five rounds. We refer to this as the direct response method. In the last five rounds, participants constructed their strategy for repeated PG games at the beginning of each round by using a one-period-ahead strategy method. ${ }^{5}$ In the strategy method, participants were asked to decide whether to cooperate in all possible one-period-ahead histories and the first period. There are eight one-period-ahead histories (two levels of each player's cooperation rate, multiplied by four levels of the other players' total cooperation rate in the previous period). The nine questions of all possible one-period-ahead histories and the first period were shown randomly. Participants could take notes about their strategic choices after constructing their strategies. The strategies were then played automatically. The participants could not change their strategies during a round.

After 10 rounds of repeated PG games, participants answered 16 questions ${ }^{6}$ from the Raven Progressive Matrices Test (Raven, 1936) in 10 minutes. The maximum test score was 16 . The total profit earned in all the rounds and periods was exchanged at a rate of $3 \mathrm{JPY}$ per point to control for the income effect. The total payment was the sum of the participation fee (1,000 JPY) and the earnings in the game.

\section{Methodology}

\subsection{Strategy Classification}

We used a one-period-ahead strategy method to investigate the types of strategies employed by the participants. ${ }^{7}$ Using this method, we can simplify and clarify the experimental results to determine the types of strategies that are significantly related to the cooperation rate.

\footnotetext{
${ }^{5}$ The strategy method for infinitely repeated games was introduced by Selten (1967). Vespa (2020) extended the strategy method into a one-period-ahead strategy method and Romero and Rosokha (2018) introduced the constructing strategy method. There is still no evidence that players employ strategies beyond two-period-ahead histories (or above) in infinitely repeated PG games. Hence, to reduce players' difficulty in eliciting strategies, we used the one-period-ahead strategy method to investigate the one-period-ahead history strategies in an infinitely repeated PG game following Dal Bó and Fréchette (2019) and Vespa (2020).

${ }^{6}$ The 16 selected questions are commonly used in Japan and Europe (see Hanaki et al., 2016). These 16 questions are selected from all 48 questions, arranged from easy to difficult.

${ }^{7}$ We also used the strategy frequency estimation method (Dal Bó \& Fréchette, 2011) to estimate strategies under the direct response method. The results are reported in the Appendix $\mathrm{C}$. We thank Dal Bó and Fréchette (2011) and Bigoni et al. (2015) for providing their code for strategy estimation.
} 
We considered 35 simplified strategies with a one-period-ahead history, which includes 20 commonly studied strategies in infinitely repeated PD games (Fudenberg et al., 2012). The strategy dataset includes unconditional cooperation (UC), GRIM, other trigger types, Tit-for-Tat (TFT) types, exploitative TFT (DTFT, also called suspicious TFT) types, false cooperator (C to All D), false defector (D to All C), alternator (DC Alternative), and unconditional defection (UD) strategies. Following Fudenberg et al. (2012), we classified these strategies into fully cooperative, fully non-cooperative, partially cooperative, lenient, forgiving, and unforgiving strategies. Our definition of leniency differs slightly from that of Fudenberg et al. (2012), who defined leniency based on a partner's history. We call this "vertical leniency." As there are three partners in our infinitely repeated PG game, we consider a strategy to be lenient when it can endure one or two partners' defection in the previous period. We call this "horizontal leniency." A description of the strategy types is presented in Table 1.

\subsection{Simulation}

In the strategy method, participants construct their strategies before interacting with their partners, and they cannot change their strategies during a round. Therefore, we expect that they construct strategies to respond to other participants in their session, but not their partners whom they do not know when constructing their strategies. Therefore, we simulated all possible group matching in each session and calculated the average cooperation rate of the constructed strategies. In each session and each round, we matched the participants to form all possible groups; for example, if the number of participants was 16 in a session, the number of all possible group matching was $\left(\begin{array}{c}16 \\ 4\end{array}\right)=\frac{16 !}{4 !(16-4) !}=1820$. We used the same number of periods in each round in each session, as in the experiments. Participants played a game fictitiously. We then calculated the average cooperation rates of HCA and LCA participants.

\section{Hypothesis}

Proto et al. (2019) investigated the relationship between cognitive ability, as measured by the Raven Progressive Matrices Test, and cooperation rate in an infinitely repeated PD game when $\delta$ is strictly higher than $\delta_{R D E}$. They found that HCA participants were more cooperative than LCA participants. Based on the results of Proto et al. (2019), we expect that HCA participants more frequently reach more efficient equilibria (i.e., RDE) than LCA participants by maximizing their expected payoff by processing rich information. In our design, UD risk dominates GRIM in $\mathrm{T} 1$ and $\mathrm{T} 2$, and GRIM risk dominates UD in T3 and T4. We expect that the cooperation rate among HCA participants is higher (lower) than that of LCA participants when $\delta$ is higher (lower) than $\delta_{R D E}$. Thus, we propose the following hypotheses:

Hypothesis 1-1: The cooperation rate among HCA participants is lower than 
Table 1 Description of strategy types

\begin{tabular}{|c|c|}
\hline Strategy & Description \\
\hline $\mathrm{UC}$ & Players always cooperate. \\
\hline GRIM & $\begin{array}{l}\text { Players cooperate if all partners cooperate; otherwise, they } \\
\text { defect. }\end{array}$ \\
\hline Trigger $X$ & $\begin{array}{l}\text { Players cooperate in the first period and continue cooperating } \\
\text { if at least } X \text { partners cooperated in the previous period; oth- } \\
\text { erwise, they defect forever. }\end{array}$ \\
\hline TFT & $\begin{array}{l}\text { Players cooperate if all partners cooperated in the previous } \\
\text { period. }\end{array}$ \\
\hline $\operatorname{TFTc} X \mathrm{~d} Y$ & $\begin{array}{l}\text { Players cooperate in the first period, and they cooperate in the } \\
\text { current period if the players cooperate and at least } X \text { partners } \\
\text { cooperated in the previous period. They also cooperate in the } \\
\text { current period if the players defect and at least } Y \text { partners } \\
\text { cooperated in the previous period. }\end{array}$ \\
\hline DTFT & $\begin{array}{l}\text { Players defect in the first period. They cooperate if all partners } \\
\text { cooperated in the previous period. }\end{array}$ \\
\hline DTFTc $X \mathrm{~d} Y$ & $\begin{array}{l}\text { Players defect in the first period, and they cooperate in the } \\
\text { current period if the players cooperate and at least } X \text { partners } \\
\text { cooperated in the previous period. They also cooperate in the } \\
\text { current period if the players defect and at least } \mathrm{Y} \text { partners } \\
\text { cooperated in the previous period. }\end{array}$ \\
\hline D to All C & Players defect first and then cooperate forever. \\
\hline C to All D & Players cooperate first and then defect forever. \\
\hline DC alternative & $\begin{array}{l}\text { Players start with defection and then alternate between coop- } \\
\text { eration and defection. }\end{array}$ \\
\hline UD & Players always defect. \\
\hline Strategy Types & Description \\
\hline Fully cooperative & $\begin{array}{l}\text { The strategies obtain full cooperation when players who } \\
\text { employ the same type of strategies are matched with each } \\
\text { other. }\end{array}$ \\
\hline Partially cooperative & $\begin{array}{l}\text { The strategies obtain a mixture of cooperation and defec- } \\
\text { tion when players who employ the same type of strategies are } \\
\text { matched with each other. }\end{array}$ \\
\hline Fully non-cooperative & $\begin{array}{l}\text { The strategies obtain full defection when players who employ } \\
\text { the same type of strategies are matched with each other. }\end{array}$ \\
\hline Lenient & $\begin{array}{l}\text { These are fully cooperative strategies that are slower to resort } \\
\text { to punishment. They include all fully cooperative strategies, } \\
\text { except UC, GRIM, and TFT; In the UC strategy, a player } \\
\text { cooperates infinitely, while in the GRIM and TFT, a player } \\
\text { cooperates infinitely only when all partners contribute fully. }\end{array}$ \\
\hline Forgiving & $\begin{array}{l}\text { These are fully cooperative strategies that are fast to forgive. } \\
\text { They include all cooperative TFT types. }\end{array}$ \\
\hline Unforgiving & $\begin{array}{l}\text { These are fully cooperative strategies that never forgive. They } \\
\text { include all cooperative trigger types. }\end{array}$ \\
\hline
\end{tabular}

that of LCA participants in $\mathrm{T} 1$.

Hypothesis 1-2: The cooperation rate among HCA participants is lower than that of LCA participants in T2. 
Hypothesis 1-3: The cooperation rate among HCA participants is higher than that of LCA participants in T3.

Hypothesis 1-4: The cooperation rate among HCA participants is higher than that of LCA participants in T4.

Dal Bó and Fréchette $(2011 ; 2019)$ revealed that when $\delta$ is set to exceed $\delta_{R D E}$, the frequency of fully cooperative strategies increases. Proto et al. (2019) suggested that HCA participants employ cooperative strategies more frequently, whereas LCA participants employ UD more frequently when $\delta$ is set to exceed $\delta_{R D E}$. We expect that fully cooperative strategies are employed more frequently by HCA participants than LCA participants when GRIM is supported as an RDE. When $\delta$ is set to be smaller than $\delta_{R D E}$, UD is RDE; hence, HCA participants employ cooperative strategies less frequently than LCA participants. Thus, we propose the following hypotheses:

Hypothesis 2-1: The frequency of fully cooperative strategies among HCA participants is lower than that of LCA participants in $\mathrm{T} 1$.

Hypothesis 2-2: The frequency of fully cooperative strategies among HCA participants is lower than that of LCA participants in T2.

Hypothesis 2-3: The frequency of fully cooperative strategies among HCA participants is higher than that of LCA participants in T3.

Hypothesis 2-4: The frequency of fully cooperative strategies among HCA participants is higher than that of LCA participants in T4.

Romero and Rosokha (2018) found that a large proportion of cooperative strategies are lenient and forgiving when $\delta$ exceeds $\delta_{R D E}$. Dal Bó and Fréchette (2011) showed that the frequency of TFT (i.e., a forgiving strategy) increases when $\delta$ exceeds $\delta_{R D E}$. We expect the same trend of leniency and forgiving in infinitely repeated PG games. We expect HCA participants to employ lenient and forgiving strategies more frequently than LCA participants when $\delta$ exceeds $\delta_{R D E}$. We may expect to observe the reverse trend when $\delta$ is smaller than $\delta_{R D E}$. Thus, we propose the following hypotheses:

Hypothesis 3-1: The frequency of forgiving strategies among HCA participants is lower than that of LCA participants in T1.

Hypothesis 3-2: The frequency of forgiving strategies among HCA participants is lower than that of LCA participants in T2.

Hypothesis 3-3: The frequency of forgiving strategies among HCA participants is higher than that of LCA participants in T3. 
Hypothesis 3-4: The frequency of forgiving strategies among HCA participants is higher than that of LCA participants in T4.

Hypothesis 4-1: The frequency of lenient strategies among HCA participants is lower than that of LCA participants in T1.

Hypothesis 4-2: The frequency of lenient strategies among HCA participants is lower than that of LCA participants in T2.

Hypothesis 4-3: The frequency of lenient strategies among HCA participants is higher than that of LCA participants in T3.

Hypothesis 4-4: The frequency of lenient strategies among HCA participants is higher than that of LCA participants in T4.

\section{Experimental Results}

A total of 172 participants participated in our experiment, consisting of eleven sessions. The average payment was 1,568 JPY in T1, 1,904 JPY in T2, 3,029 JPY in T3, and 4,128 JPY in T4. Each session lasted for two hours in T1, T2 and $\mathrm{T} 3$, and three hours in $\mathrm{T} 4$. On average, there were 1.5 periods per round in $\mathrm{T} 1,2.5$ periods per round in T2, 6 periods per round in T3, and 9 periods per round in T4. Table 2 presents a summary of the experiments.

Table 2 Summary of the experiments

\begin{tabular}{|c|c|c|c|c|}
\hline & Treatment 1 & Treatment 2 & Treatment 3 & Treatment 4 \\
\hline Number of sessions & 3 & 3 & 3 & 2 \\
\hline Number of participants & 48 & 40 & 44 & 40 \\
\hline $\begin{array}{l}\text { The average number of } \\
\text { rounds }{ }^{1}\end{array}$ & 10 & 10 & 10 & 9.5 \\
\hline $\begin{array}{l}\text { The average number of periods } \\
\text { per round }\end{array}$ & 1.5 & 2.5 & 6 & 9 \\
\hline Average payment (JPY) & 1568 & 1904 & 3029 & 4128 \\
\hline Exchange rate (JPY/point) & 3 & 3 & 3 & 3 \\
\hline Raven score & 11.25 & 10.975 & 11.545 & 11.1 \\
\hline Male & $56.25 \%$ & $42.5 \%$ & $56.818 \%$ & $57.5 \%$ \\
\hline Age & 21.021 & 19.95 & 20.773 & 20 \\
\hline $\begin{array}{l}\text { Economics or business stu- } \\
\text { dents }\end{array}$ & $8.333 \%$ & $27.5 \%$ & $20.455 \%$ & $32.5 \%$ \\
\hline
\end{tabular}

\footnotetext{
${ }^{1}$ Due to time constraint, we conducted nine rounds in one session in Treatment 3.
}

To check the balance of cognitive ability among the four treatments, we conducted a one-way ANOVA to compare average Raven scores: 11.25 in T1, 10.975 in $\mathrm{T} 2,11.545$ in $\mathrm{T} 3$, and 11.1 in $\mathrm{T} 4$, with no significant difference $(p=0.775)$. We considered participants who had Raven scores above the mean 
as HCA participants and those who had Raven scores below or equal to the mean as LCA participants. There were 28, 14, 26, and 22 participants whose Raven scores were above 11 in T1, T2, T3 and T4, respectively. Meanwhile, 20, 26, 18, and 18 participants had Raven scores below or equal to 11 in T1, T2, T3 and T4, respectively. Figure 1 shows the distribution of the Raven score for each treatment.

Fig. 1 The distribution of the Raven score in each treatment

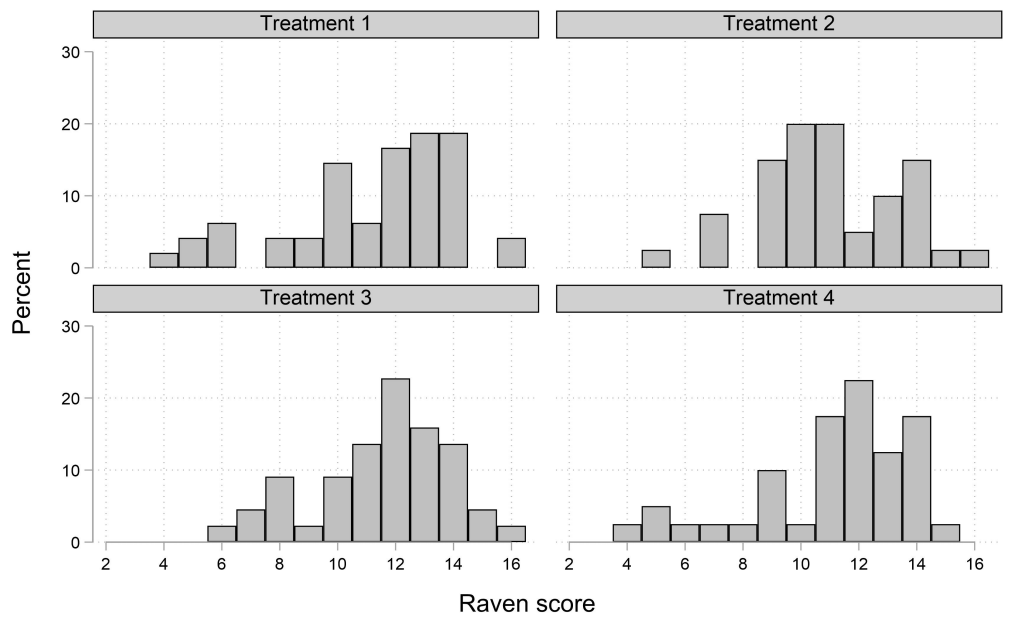

We have also checked the balance of gender, age, and economics or business students among the four treatments by conducting a one-way ANOVA. We found a $1 \%$ significant difference among treatments on age and a $5 \%$ significant difference among treatment on economics or business students, but no significant difference on male $(p=0.474)$.

In the analysis of average cooperation rate and the frequency of strategy types, we control demographic characteristics including gender, age, and economics or business students.

\subsection{Average Cooperation Rate}

Figure 2 shows the average cooperation rate (\%) across rounds between HCA participants and LCA participants. We report two types of results: average cooperation rate in period 1 only and all periods. Participants make decision under direct response method from round 1 to 5 and strategy method from round 6 to 10. In treatment 1, HCA participants always cooperated less than LCA participants for both period 1 and all periods. In treatment 2 , the average cooperation rate between HCA participants and LCA participants was similar across rounds. In treatment 3, HCA participants cooperated more than LCA participants in period 1 after round 2. HCA participants cooperated more than LCA participants in all periods from round 2 to round 5 and then behaved 
similarly from round 6 . In treatment $4, \mathrm{HCA}$ participants always cooperated more than LCA participants in period 1 after round 2. However, HCA participants sometimes cooperated more and sometimes less than LCA participants in all periods across rounds.

Fig. 2 Average cooperation rate across rounds between HCA participants and LCA participants

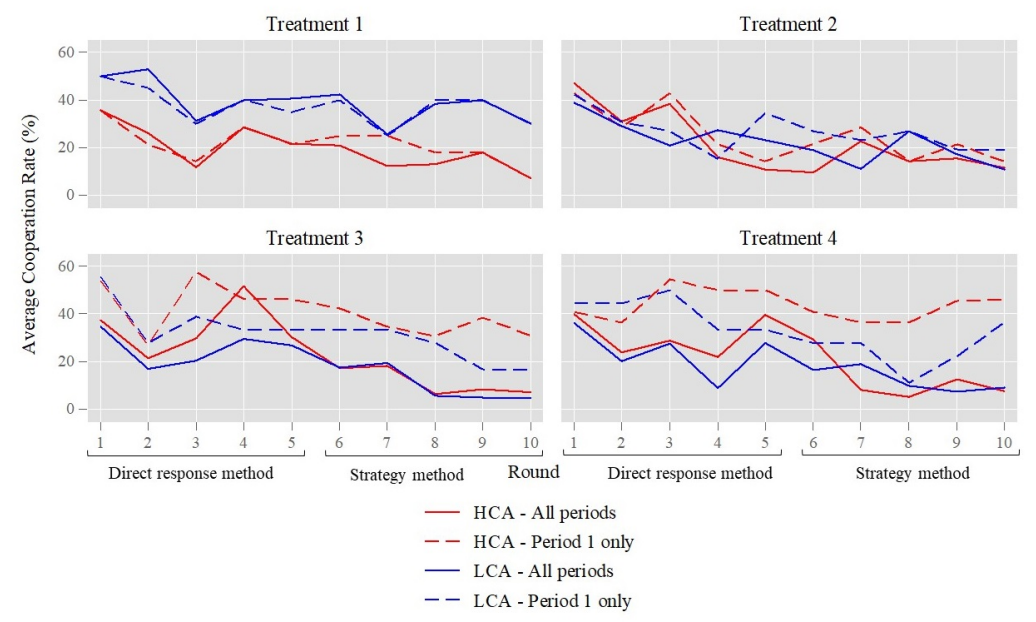

We examined our hypothesis that HCA participants are more (less) likely to cooperate than LCA participants in T3 and T4 (T1 and T2) in period 1 and all periods, in which participants behave according to RDE. We examined our hypothesis by reporting two types of results: experimental results under the direct response method (rounds 1 to 5 ) and simulation results using strategy method observation. ${ }^{8}$

Figure 3 shows the predicted average cooperation rate (\%) between HCA and LCA participants under the direct response method (rounds 1 to 5), and strategy method (simulation) in (a) Treatment 1, (b) Treatment 2, (c) Treatment 3 and (d) Treatment 4 . We provide the results of period 1 only and all periods. For each pairwise comparison between HCA and LCA participants in each treatment, we report the results of logistic regression of cooperation rate, with HCA participants as the dummy independent variable, controlling for demographic variables, including age, gender, and economics major. ${ }^{9} \mathrm{We}$ report robust standard errors clustered by group. We define a $p$-value less than or equal to 0.05 , which is typically $\leq 0.05$, as statistically significant. We report the predicted average cooperation rate (predicted probabilities) presented by

\footnotetext{
${ }^{8}$ We report the results of experimental data from strategy method (round 6 to 10) in Table A12 in Appendix D.

${ }^{9}$ We also conducted the unconditional logistic regression of cooperation rate, with HCA participants as the dummy independent variable, without controlling for demographic variables and robust standard errors clustered by group. The results are shown in Table A18 and Table A20 in Appendix E.
} 
rectangular bars and standard errors of the predicted average cooperation rate presented by error bars. ${ }^{10}$

Fig. 3 Predicted Average Cooperation Rate (\%) between HCA and LCA participants under the direct response method and strategy method (simulation) in (a) Treatment 1, (b) Treatment 2, (c) Treatment 3, and (d) Treatment 4

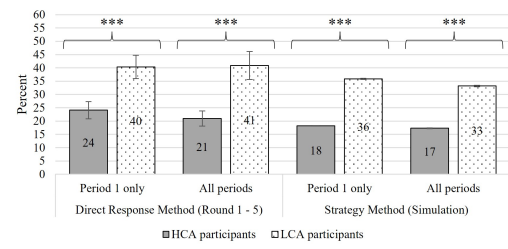

(a) Treatment 1

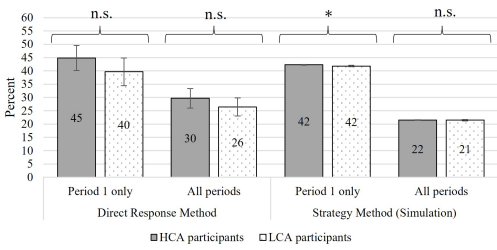

(c) Treatment 3

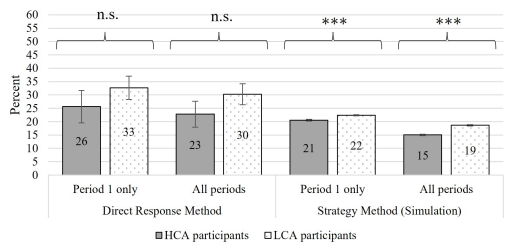

(b) Treatment 2

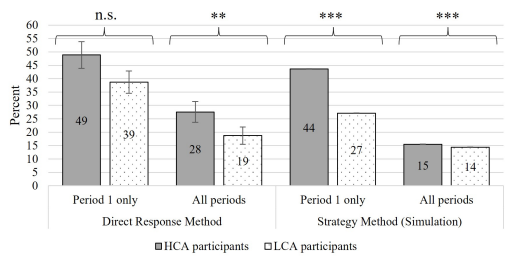

(d) Treatment 4

Notes:Predicted average cooperation rates and $p$-values are calculated based on logistic regression of cooperation rate, with HCA participants as dummy independent variable, controlling for demographic characteristics (including age, gender, and economics major), with robust standard errors clustered by group. *,**, and *** indicate significance at the $0.10,0.05$, and 0.01 levels, respectively. n.s. means the difference is not statistically significant at 0.1 . See Table A11 and Table A13 in Appendix D.

\section{(a) Treatment 1}

Under the direct response method, the predicted average cooperation rate of HCA participants was always lower than that of LCA participants for both period 1 (HCA: $24 \%$ and LCA: 40\%) and all periods (HCA: $21 \%$ and LCA: $41 \%)$. These differences were not statistically significant. Under the strategy method (simulation), the predicted average cooperation rate of HCA participants was always lower than that of LCA participants for both period 1 (HCA: 18\% and LCA: 36\%) and all periods (HCA: $17 \%$ and LCA: 33\%). These differences between the HCA and LCA participants were statistically significant. Thus, Hypothesis 1-1 was supported.

(b) Treatment 2

Under the direct response method, the predicted average cooperation rate of HCA participants was lower than that of LCA participants for both period 1 (HCA: $26 \%$ and LCA: $33 \%$ ) and all periods (HCA: $23 \%$ and LCA: $30 \%$ ), and

\footnotetext{
${ }^{10}$ All regression results are shown in Table A11 and A13 in Appendix D.
} 
these differences were not statistically significant. Under the strategy method (simulation), the predicted average cooperation rate of $\mathrm{HCA}$ participants was lower than that of LCA participants for both period 1 (HCA: 21\% and LCA: $22 \%$ ) and all periods (HCA: $15 \%$ and LCA: 19\%), and these differences were statistically significant. ${ }^{11}$ Thus, Hypothesis 1-2 was not supported in direct response method, but supported in strategy method (simulation).

(c) Treatment 3

Under the direct response method, the predicted average cooperation rate of HCA participants was higher than that of LCA participants in both period 1 (HCA: $45 \%$ and LCA: 40\%) and all periods (HCA: $30 \%$ and LCA: $26 \%$ ). These differences were not statistically significant. Under the strategy method (simulation), the predicted average cooperation rate of $\mathrm{HCA}$ participants was similar to that of LCA participants in both period 1 (HCA: $42.3 \%$ and LCA $41.8 \%$ ) and all periods (HCA:22\% and LCA: $21 \%$ ). These differences were not statistically significant. ${ }^{12}$ Thus, Hypothesis $1-3$ was not supported.

(d) Treatment 4

Under the direct response method (rounds 1 to 5), the predicted average cooperation rate of HCA participants was higher than that of LCA participants in both period 1 (HCA: $49 \%$ and LCA: $39 \%$ ) and all periods (HCA: $28 \%$ and LCA: $19 \%$ ), and these differences were not statistically significant in period 1 , but statistically significant in all periods. ${ }^{13}$ Under the strategy method (simulation), the predicted average cooperation rate of $\mathrm{HCA}$ participants was higher than that of LCA participants in both period 1 (HCA: $44 \%$ and LCA: $27 \%$ ) and all periods (HCA: 15\% and LCA: 14\%), and these differences were statistically significant. Thus, Hypothesis 1-4 was supported, except in period 1 in direct response method.

\subsection{Strategy analysis}

We examined our hypothesis that HCA participants more (less) frequently employ fully cooperative, forgiving, and lenient strategies than LCA participants in T3 and T4 (T1 and T2), in which participants behave according to RDE. We report the predicted frequency of strategies using the strategy method (rounds 6 to 10 ).

Figure 4 shows the predicted frequency (\%) of the (a) fully cooperative strategy, (b) forgiving strategy, and (c) lenient strategy between HCA and LCA

\footnotetext{
${ }^{11}$ In the results of unconditional logistic regression (i.e., without controlling demographic variables), in strategy method (simulation) in Treatment 2 , the average cooperation rate of HCA participants and LCA participants were not statistically significant in period 1 (HCA: $21 \%$ and LCA: $22 \%$ ) and all periods (HCA: $17 \%$ and LCA: $17 \%$ ).

${ }^{12}$ In the results of unconditional logistic regression (i.e., without controlling demographic variables), in strategy method (simulation) in Treatment 3 , the average cooperation rate of HCA participants is higher than that of LCA participants in both period 1 (HCA: $44 \%$ and LCA:39\%) and all periods (HCA: $22 \%$ and LCA: $20 \%$ ) with statistically significant.

${ }^{13}$ In the results of unconditional logistic regression (i.e., without controlling demographic variables), in strategy method (simulation) in Treatment 4, the average cooperation rate of HCA participants and LCA participants were not statistically significant in period 1 (HCA: $46 \%$ and LCA: $41 \%$ ) and all periods (HCA: $27 \%$ and LCA: $19 \%$ ).
} 
participants. For each pairwise comparison between HCA and LCA participants in each treatment, we report the results of logistic regression of strategy types, with HCA participants as the dummy independent variable, controlling for demographic variables, including age, gender, and economics major. ${ }^{14} \mathrm{We}$ report robust standard error. We report the predicted frequency (predicted probabilities) presented by rectangular bars and standard errors of predicted frequency presented by error bars. ${ }^{15}$

Fig. 4 The predicted frequency (\%) of (a) fully cooperative strategy, (b) forgiving strategy, and (c) lenient strategy between HCA and LCA participants under strategy method in each treatment

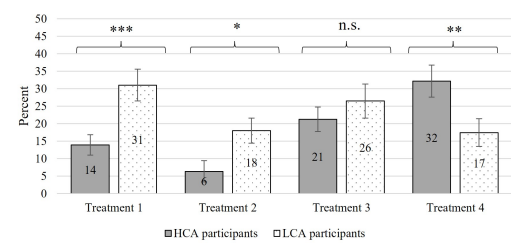

(a) Fully cooperative strategy

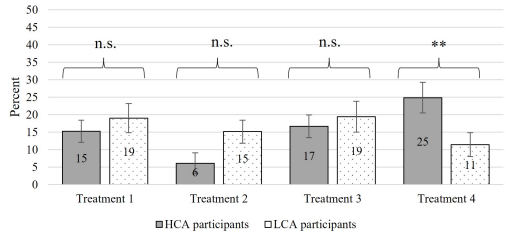

(b) Forgiving strategy

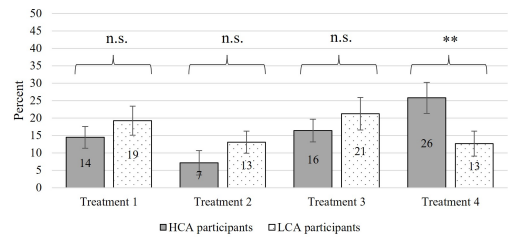

(c) Lenient strategy

Notes:Predicted frequency and $p$-values are calculated based on logistic regression of strategy types, with HCA participants as dummy independent variable, controlling for demographic characteristics (including age, gender, and economics major), with robust standard errors. *, **, and $* * *$ indicate significance at the $0.10,0.05$, and 0.01 level, respectively. See Table A14 to A16 in Appendix D.

(a) Fully cooperative strategy

In Treatment 1, the predicted frequency of the fully cooperative strategy among HCA participants was $14 \%$ lower than that of LCA participants (31\%), and these differences were statistically significant. Thus, Hypothesis 2-1 was supported. In Treatment 2, the predicted frequency of the fully cooperative strategy among HCA participants was $6 \%$ lower than that of LCA participants $(18 \%)$, and these differences were not statistically significant. Thus, Hypothesis 2-2 was not supported. In Treatment 3 , the predicted frequency of the

\footnotetext{
${ }^{14}$ We also conducted the unconditional logistic regression of strategy types, with HCA participants as the dummy independent variable, without controlling for demographic variables and robust standard errors. The results are shown in Table A21 to A23 in Appendix E.

${ }^{15}$ All regression results are shown in Table A14 to A16 in Appendix D.
} 
fully cooperative strategy among HCA was $21 \%$ and that of LCA participants was $26 \%$, with no statistically significant differences. Thus, Hypothesis 2-3 was not supported. In Treatment 4 , the predicted frequency of the fully cooperative strategy among HCA participants was $32 \%$ higher than that of LCA participants $(17 \%)$ and these differences were statistically significant. ${ }^{16}$ Thus, Hypothesis 2-4 was supported.

(b) Forgiving strategy

In Treatment 1, the predicted frequency of the forgiving strategy among HCA participants was $15 \%$ lower than that of LCA participants (19\%), without statistically significant differences. Thus, Hypothesis 3-1 was not supported. In Treatment 2, the predicted frequency of the forgiving strategy among HCA participants was $6 \%$ lower than that of LCA participants $(15 \%)$, without statistically significant differences. Thus, Hypothesis 3-2 was not supported. In Treatment 3, the predicted frequency of the forgiving strategy among HCA was $17 \%$ lower than that of LCA participants (19\%), without statistically significant differences. Thus, Hypothesis 3-3 was not supported. In Treatment 4, the predicted frequency of the forgiving strategy among HCA participants was $25 \%$ higher than that among LCA participants (11\%), and these differences were statistically significant. Thus, Hypothesis 3-4 was supported.

(c) Lenient strategy

In Treatment 1, the predicted frequency of the lenient strategy among HCA participants was $14 \%$ lower than that of LCA participants (19\%), with no statistically significant difference. Thus, Hypothesis 4-1 was not supported. In Treatment 2, the predicted frequency of the lenient strategy among HCA participants was $7 \%$ lower than that of LCA participants (13\%), with no statistically significant difference. Thus, Hypothesis 4-2 was not supported. In Treatment 3, the predicted frequency of the lenient strategy among HCA participants was $16 \%$, which is lower than the $21 \%$ for LCA participants, with no statistically significant difference. Thus, Hypothesis 4-3 was not supported. In Treatment 4, the frequency of the lenient strategy among HCA participants was $26 \%$ higher than that of LCA participants (13\%), and these differences were statistically significant. Thus, Hypothesis 4-4 was supported.

\section{Discussion}

In the theoretical prediction, GRIM risk dominates UD when $\delta \geq \delta_{R D E}$. In our experiment, we set $\delta_{T 3}=0.8$, which is $\delta_{R D E}$. We expect HCA participants to reach more efficient equilibria (i.e., RDE) more frequently than LCA participants by maximizing their expected payoff, which is achieved by processing rich information. However, at $\delta_{T 3}=\delta_{R D E}$, the expected payoff employing GRIM is the same as that employing UD. Thus, we focus on the comparison between $\mathrm{T} 1$ and $\mathrm{T} 4$, or T2 and T4 for investigating the effect of continuation

\footnotetext{
${ }^{16}$ In the results of unconditional logistic regression (i.e., without controlling demographic variables), in Treatment 4 , the frequency of fully cooperative strategies among HCA participants and LCA participants was not statistically significant (HCA: $31 \%$ and LCA: 18\%).
} 
probability (i.e., whether GRIM is supported as the RDE or not) on behaviors among treatments for each type of participant.

Focusing on the direct response method, the cooperation rate of HCA participants in period 1 and all periods increased as the expected payoff of GRIM exceeded that of UD from Treatment 1 to $4(p<0.01$ for period 1 and $p<0.05$ for all periods; see Table A17 in Appendix D) and from Treatment 2 to 4 $(p<0.01$ for period 1 and $\mathrm{p}=0.859$ for all periods; see Table A17 in Appendix D). This implies that HCA participants cooperated more in T4 than in T1 or $\mathrm{T} 2$ in period 1 , in order to maximize their expected payoff.

However, the cooperation rate of LCA participants in the direct response method remained unchanged in period 1 and decreased in all periods from Treatment 1 to 4 ( $p=0.271$ for period 1 and $p<0.01$ for all periods; see Table A17 in Appendix D) and 2 to 4 ( $p=0.490$ for period 1 and $\mathrm{p}=0.025$ for all periods, see Table A17 in Appendix D). This implies that LCA participants tended to cooperate in period 1 due to similar frequencies in T1, T2, and $\mathrm{T} 4$, but defected more in all periods in $\mathrm{T} 4$ than they did in $\mathrm{T} 1$ or $\mathrm{T} 2$. As the frequency of fully non-cooperative strategies was more than $50 \%$ among HCA participants and LCA participants in all treatments (see Table A10 in Appendix C), the level of cooperation did not evolve if there was a large fraction of fully non-cooperative strategies. The average number of periods per round was higher in $\mathrm{T} 4$ than in $\mathrm{T} 1$ and $\mathrm{T} 2$. Therefore, the high frequency of fully non-cooperative strategies decreased the cooperation rate in all periods in $\mathrm{T} 4$, as compared to that in $\mathrm{T} 1$ and $\mathrm{T} 2$.

In the direct response method, we found that hypotheses 1-1 and 1-4 were supported, and hypotheses 1-2 and 1-3 were not supported. The background for these results was built up in two aspects: 1) LCA participants cooperated more than HCA participants with statistical significance $(p<0.01$ for period 1 and all periods) in T1. 2) LCA participants decreased cooperation and HCA participants increased cooperation as $\delta$ increased and exceeded $\delta_{R D E}$ (see Table A17 in Appendix D). Because the trend of cooperation rate was reversed between HCA and LCA participants as $\delta$ increased, the statistically significant difference in the cooperation rate in $\mathrm{T} 1$ was rendered insignificant from $\mathrm{T} 1$ to $\mathrm{T} 2$ and $\mathrm{T} 3$. Moreover, the cooperation rate of HCA participants exceeded that of LCA participants from T1 to T4.

We found that Hypotheses 2-1 and 2-4 were supported but Hypotheses 2-2 and 2-3 were not. We confirmed these results by examining the differences in the trend of the fully cooperative strategies between HCA and LCA participants. HCA participants employed fully cooperative strategies from Treatment 1 to $4(p<0.01$, see Table A17 in Appendix D) and 2 to $4(p<0.01$, see Table A17 in Appendix D) more frequently. However, the frequency of fully cooperative strategies employed by LCA participants was not statistically different between Treatments 1 and 4 ( $p=0.056$, see Table A17 in Appendix D) and Treatment 2 and 4 ( $p=0.385$, see Table A17 in Appendix D).

Similar to the trends in the cooperation rate between HCA and LCA participants, the reversed trends in the frequency of fully cooperative strategies 
between the two groups of participants, along with LCA participants employing fully cooperative strategies more frequently than HCA participants in T1, builds up the background for the results testing Hypotheses 2-1 to 2-4. The difference in the frequency of fully cooperative strategies between the two types of participants was diminished came closer as $\delta$ increased from $\mathrm{T} 1$ to T3, and HCA participants turned to employ fully cooperative strategies more frequently than LCA participants in T4.

Our experimental results suggested the lag effects of the continuation probability (i.e., whether GRIM is supported as the RDE) on the cooperation rate and the frequency of fully cooperative strategies. HCA participants did not change their strategy from fully non-cooperative strategies, including UD, to fully cooperative strategies including GRIM and TFT as soon as $\delta$ exceeded $\delta_{R D E}$ or the expected payoff of GRIM exceeded that of UD. Instead, HCA participants gradually switched from fully non-cooperative strategies to fully cooperative strategies. These changes in the strategy profiles of HCA participants caused the cooperation rate to gradually increase as $\delta$ increased. However, LCA participants tended to maintain the initial relatively high cooperation rate, as $\delta$ increased, by maintaining the initial strategy profiles in T1. Thus, our hypotheses were supported in T1 and T4, where $\delta$ was far away from $\delta_{R D E}$, but not supported in T2 and T3, where $\delta$ was relatively closer to $\delta_{R D E}$.

\section{Conclusion}

In this study, we designed an infinitely repeated PG game experiment under different $\delta$. We designed two treatments for which the continuation probability was lower than the $\delta_{R D E}$ and two treatments in which the continuation probability was higher than the $\delta_{R D E}$. We investigated the differences in cooperation rates and strategies between $\mathrm{HCA}$ and LCA participants.

We found that 1 ) the average cooperation rate of HCA participants was statistically significantly lower than that of LCA participants in T1. 2) The average cooperation rate of $\mathrm{HCA}$ participants was statistically significantly lower than that of LCA participants in T2 in the simulation results with strategy method, but not in direct response method. 3) The average cooperation rate of HCA participants was not statistically significantly different from that of LCA participants in T3, which continuation probability was the same as the $\left.\delta_{R D E}, 4\right)$ the average cooperation rate of HCA participants was statistically significantly higher than that of LCA participants in $\mathrm{T} 4,5$ ) the frequency of fully cooperative strategies for HCA participants was statistically lower than that for LCA participants in T1, but not different in T2,6) the frequency of fully cooperative strategies for HCA participants was statistically higher than that for LCA participants in T4, but not different in T3, and 7) the frequency of lenient and forgiving strategies for HCA participants was statistically higher than that for LCA participants, but only in T4; they were not different in other treatments. 
In the future, we aim to follow Proto et al. (2019)'s experimental design to separate HCA and LCA participants to play the infinitely repeated PG game. HCA participants will only match with HCA partners, and LCA participants will only match with LCA partners. We would like to confirm whether mutual cooperation can be maintained when the group players are all HCA participants and when the GRIM is supported as an RDE. It will also be interesting to conduct experiments with the different types of strategy methods. In the strategy methods, participants choose their strategy from a strategy set consisting of UD, GRIM, lenient Trigger, TFT, and lenient TFT strategies. By doing so, we can directly test the theoretical prediction on RDE condition. This enables us to investigate the relationship between the cognitive abilities of participants and the types of strategies employed: cooperative/defective, lenient/not lenient, and forgiving/unforgiving strategies, with great depth.

\section{References}

Al-Ubaydli, O., Jones, G., Weel, J. (2016). Average player traits as predictors of cooperation in a repeated prisoner's dilemma. Journal of Behavioral and Experimental Economics, 64, 50-60.

Aoyagi, M., Bhaskar, V., Fréchette, G.R. (2019). The impact of monitoring in infinitely repeated games: Perfect, public, and private. American Economic Journal: Microeconomics, 11(1), 1-43.

Barreda-Tarrazona, I., Jaramillo-Gutiérrez, A., Pavan, M., Sabater-Grande, G. (2017). Individual characteristics vs. experience: An experimental study on cooperation in prisoner's dilemma. Frontiers in psychology, 8, 596.

Bigoni, M., Casari, M., Skrzypacz, A., Spagnolo, G. (2015). Time horizon and cooperation in continuous time. Econometrica, 83(2), 587-616.

Blonski, M., Ockenfels, P., Spagnolo, G. (2011). Equilibrium selection in the repeated prisoner's dilemma: Axiomatic approach and experimental evidence. American Economic Journal: Microeconomics, 3(3), 164-92.

Brañas-Garza, P., García-Muñoz, T., González, R.H. (2012). Cognitive effort in the beauty contest game. Journal of Economic Behavior \& Organization, 83(2), 254-260.

Carlsson, H., \& Van Damme, E. (1993). Equilibrium selection in stag hunt games. Frontiers of game theory, 237. 
Carpenter, J., Graham, M., Wolf, J. (2013). Cognitive ability and strategic sophistication. Games and Economic Behavior, 80, 115-130.

Dal Bó, P., \& Fréchette, G.R. (2011). The evolution of cooperation in infinitely repeated games: Experimental evidence. American Economic Review, $101(1), 411-29$.

Dal Bó, P., \& Fréchette, G.R. (2019). Strategy choice in the infinitely repeated prisoner's dilemma. American Economic Review, 109(11), 3929-52.

Dreber, A., Fudenberg, D., Rand, D.G. (2014). Who cooperates in repeated games: The role of altruism, inequity aversion, and demographics. Journal of Economic Behavior \& Organization, 98, 41-55.

Duffy, J., \& Ochs, J. (2009). Cooperative behavior and the frequency of social interaction. Games and Economic Behavior, 66(2), 785-812.

Fischbacher, U. (2007). z-tree: Zurich toolbox for ready-made economic experiments. Experimental economics, 10(2), 171-178.

Fréchette, G.R., \& Yuksel, S. (2017). Infinitely repeated games in the laboratory: Four perspectives on discounting and random termination. Experimental Economics, 20(2), 279-308.

Fudenberg, D., Rand, D.G., Dreber, A. (2012). Slow to anger and fast to forgive: Cooperation in an uncertain world. American Economic Review, 102(2), 720-49.

Gill, D., \& Prowse, V. (2016). Cognitive ability, character skills, and learning to play equilibrium: A level-k analysis. Journal of Political Economy, $124(6), 1619-1676$.

Hanaki, N., Jacquemet, N., Luchini, S., Zylbersztejn, A. (2016). Fluid intelligence and cognitive reflection in a strategic environment: evidence from dominance-solvable games. Frontiers in psychology, 7, 1188. 
Harsanyi, J.C., Selten, R., et al. (1988). A general theory of equilibrium selection in games. MIT Press Books, 1.

Jones, G. (2008). Are smarter groups more cooperative? evidence from prisoner's dilemma experiments, 1959-2003. Journal of Economic Behavior \& Organization, 68(3-4), 489-497.

Kawamura, T., \& Ogawa, K. (2019). Cognitive ability and human behavior in experimental ultimatum games. Research in Economics, 73(1), 97-106.

Kim, Y. (1996). Equilibrium selection inn-person coordination games. Games and Economic Behavior, 15(2), 203-227.

Lugovskyy, V., Puzzello, D., Sorensen, A., Walker, J., Williams, A. (2017). An experimental study of finitely and infinitely repeated linear public goods games. Games and Economic Behavior, 102, 286-302.

Palfrey, T.R., \& Rosenthal, H. (1994). Repeated play, cooperation and coordination: An experimental study. The Review of Economic Studies, 61(3), $545-565$.

Proto, E., Rustichini, A., Sofianos, A. (2019). Intelligence, personality, and gains from cooperation in repeated interactions. Journal of Political Economy, 127(3), 1351-1390.

Raven, J.C. (1936). Mental tests used in genetic studies: The performance of related individuals on tests mainly educative and mainly reproductive. Unpublished master's thesis, University of London.

Romero, J., \& Rosokha, Y. (2018). Constructing strategies in the indefinitely repeated prisoner's dilemma game. European Economic Review, 104, $185-219$.

Sell, J., \& Wilson, R.K. (1999). The maintenance of cooperation: expectations of future interaction and the trigger of group punishment. Social Forces, $77(4), 1551-1571$. 
Selten, R. (1967). Die strategiemethode zur erforschung des engeschraänkt rationalen verhaltens im rahmen eines oligopolexperiments. H. Sauermann (Ed.), Beiträge zuer experimentellen wirtschaftsforschung (pp. 136-168). Tübingen: J. C. B. Mohr.

Tan, L., \& Wei, L. (2014). Voluntary contribution mechanism played over an infinite horizon. Pacific Economic Review, 19(3), 313-331.

Vespa, E. (2020). An experimental investigation of cooperation in the dynamic common pool game. International Economic Review, 61(1), 417-440. 
Supplementary information. Supplementary material is available at journal's website

Acknowledgments. We would like to thank the editor, the co-editor, and the anonymous referees. We are grateful to Takanori Ida, Kazuhito Ogawa, Hajime Kobayashi, Tadashi Sekiguchi, Hisaki Kono, Yohei Mitani, Masaki Aoyagi, Nobuyuki Hanaki and Masao Ogaki, as well as the participants at the International Workshop for Lab and Field Experiments and the 21st Experimental Social Sciences Conference, Kansai University for their helpful conversations and comments. We thank the Kansai University Center for Experimental Economics for the use of experimental laboratories and participant recruiting system. Research support was provided by Japan Society for the Promotion of Science KAKENHI Grant Numbers (JP17J03485, JP20H05631). The experiment reported in this paper is approved by Research Ethic Committee at The Research Institute for Socionetwork Strategies (RISS), Kansai University.

\section{Declarations}

- Funding

We gratefully acknowledge the financial support from Japan Society for the Promotion of Science KAKENHI Grant Numbers (JP17J03485, JP20H05631).

- Conflict of interest/Competing interests

The authors declare that they have no conflict of interest.

- Ethics approval

The experiment reported in this paper is approved by Research Ethic Committee at The Research Institute for Socionetwork Strategies (RISS), Kansai University.

- Consent to participate

All participants signed the consent form to agree to participate this experiments.

- Consent for publication

All participants signed the consent form to agree to publish the experimental data under the condition of anonymity.

- Availability of data and materials

Supplementary material is available at journal's website.

- Code availability

Code used in analysis is available at journal's website

- Authors' contributions

The authors contributed equally to this work. 


\section{NOT FOR PUBLICATION}

Online Supplementary Appendix to:

Kawamura and Tse: ${ }^{1}$ "Intelligence promotes cooperation in long-term interaction: Experimental evidence in infinitely repeated public goods games"

Tables of Contents

Appendix A: Calculation of the risk dominant threshold

Appendix B: Description of a strategic plan

Appendix C: Strategy analysis results

Appendix D: Regression Results for figures

Appendix E: Analyses of experimental results unconditional on personal characteristics

Appendix F: The frequency of unconditional defection strategy between HCA participants and LCA participants

Appendix G: Average payoff between HCA participants and LCA participants

Appendix H: Experimental instruction

${ }^{1}$ Kawamura: Tezukayama University (kawamuratetsuya2027@gmail.com),Tse: Osaka University (tiffany.ttk@gmail.com) 


\section{A. Calculation of the risk dominant threshold}

Carlsson and van Damme (1993) and Kim (1996) explore Harsanyi and Selten (1988)'s notion of risk dominance in two-person to n-person games. Using Kim's method of calculating the expected payoff, we show the expected payoff using UD and GRIM under the same probability to find the possible RDE strategies that can minimize strategic risk.

We consider a game with these two pure SPE strategies (UD and GRIM) ${ }^{2}$. The possible situations for a given individual are thus all the combinations of that individual playing GRIM or UD against three partners, with $\mathrm{k}$ partners playing GRIM and (3-k) partners playing UD, for any $0 \leq \mathrm{k} \leq 3$. We denote the payoff when a player plays GRIM against k partners playing GRIM by $\alpha_{k}$ and the payoff when a player plays UD against $\mathrm{k}$ partners playing GRIM by $\beta_{k}$.

There are four possible events: all three partners choose UD, one partner chooses GRIM and two partners choose UD, two partners choose GRIM and one partner chooses UD, and all three partners choose GRIM. Each partner chooses GRIM with probability $y_{\text {Grim }}$ and UD with probability $y_{U D}$, where $y_{U D}=1-y_{\text {Grim }}$. To simplify, following Dal Bó and Fréchette (2011), we assume that each partner chooses GRIM and UD with the same probability, where $y_{G R I M}=\frac{1}{2}$ and $y_{U D}=\frac{1}{2}$. The probability of a given player facing with $\mathrm{k}$ players employing GRIM and 3-k players employing UD is given in the following formula:

$$
\text { Probability }=\left(\begin{array}{l}
3 \\
k
\end{array}\right) \times\left(y_{\text {Grim }}\right)^{k} \times\left(y_{U D}\right)^{3-k}=\left(\begin{array}{l}
3 \\
k
\end{array}\right) \times\left(\frac{1}{2}\right)^{k} \times\left(\frac{1}{2}\right)^{3-k}=\left(\begin{array}{l}
3 \\
k
\end{array}\right) \times\left(\frac{1}{8}\right)
$$

$\left(\begin{array}{l}3 \\ k\end{array}\right)$ indicates the combined probability of selecting k partners choosing GRIM from all three partners.

$\left(y_{\text {Grim }}\right)^{k}$ indicates the combined probability of the multiple individual probabilities of $\mathrm{k}$ partners employing GRIM. $\left(y_{U D}\right)^{3-k}$ indicates the combined probability of the multiple individual probabilities of (3-k) partners employing UD. Table A1 shows the expected payoff using UD and GRIM against the three partners.

2 To prove that GRIM is supported as the SPE, we need to show that no subject has an incentive to deviate from the equilibrium path. On the equilibrium path, if player $i$ follows GRIM, his/her payoff is given by $\pi_{i}(G R I M)=$ $\frac{1}{1-\delta}\left(0.5 \sum_{i=1}^{4} 10\right)=\frac{20}{1-\delta}$. While if he/she deviates, he/she receives a one-shot gain followed by lower future payoffs: $\pi_{i}(D \mid G R I M)=\left(10+0.5 \sum_{i \neq j} 10\right)+\frac{\delta}{1-\delta} 10=25+\frac{10 \delta}{1-\delta}$. Thus, a player has no incentive to deviate from the equilibrium path when $\pi_{i}(G R I M) \geq \pi_{i}(D \mid G R I M)$. Therefore, the threshold value of probability continuation which GRIM is supported as SPE $\delta_{\mathrm{SPE}}$ is $\frac{1}{3}$. 
Table A1. Expected payoff using the possible SPE strategies (UD and GRIM)

Partners

\begin{tabular}{|c|c|c|c|c|}
\hline Player $i$ & $3 U D$ & 1GRIM+2UD & 2GRIM+1UD & 3GRIM \\
\hline GRIM & $5+\frac{10 \delta}{1-\delta}$ & $10+\frac{10 \delta}{1-\delta}$ & $15+\frac{10 \delta}{1-\delta}$ & $\frac{20}{1-\delta}$ \\
\hline UD & $\frac{10}{1-\delta}$ & $15+\frac{10 \delta}{1-\delta}$ & $20+\frac{10 \delta}{1-\delta}$ & $25+\frac{10 \delta}{1-\delta}$ \\
\hline Probability & $\frac{1}{8}$ & $\frac{3}{8}$ & $\frac{3}{8}$ & $\frac{1}{8}$ \\
\hline
\end{tabular}

GRIM risk dominates UD if

$$
\begin{gathered}
\pi_{G R I M}=\sum_{k=0}^{3}\left(\begin{array}{l}
3 \\
k
\end{array}\right)\left(\frac{1}{8}\right) \alpha_{k} \geq \sum_{k=0}^{3}\left(\begin{array}{l}
3 \\
k
\end{array}\right)\left(\frac{1}{8}\right) \beta_{k}=\pi_{U D} \\
\frac{1}{8}\left(5+\frac{10 \delta}{1-\delta}\right)+\frac{3}{8}\left(10+\frac{10 \delta}{1-\delta}\right)+\frac{3}{8}\left(15+\frac{10 \delta}{1-\delta}\right)+\frac{1}{8}\left(\frac{20}{1-\delta}\right) \geq \\
\geq \frac{1}{8}\left(\frac{10}{1-\delta}\right)+\frac{3}{8}\left(15+\frac{10 \delta}{1-\delta}\right)+\frac{3}{8}\left(20+\frac{10 \delta}{1-\delta}\right)+\frac{1}{8}\left(25+\frac{10 \delta}{1-\delta}\right) \\
\delta_{R D E} \geq \frac{4}{5}
\end{gathered}
$$

\section{B. Description of a strategic plan}

Table A2. Description of a strategic plan

\begin{tabular}{|l|c|c|c|}
\hline Choice & Own Contribution at t-1 & Partners' Contribution at t-1 & What is your contribution at t? \\
\hline 1 & 0 & 0 & 0 or $10 ?$ \\
\hline 2 & 0 & 10 & 0 or $10 ?$ \\
\hline 3 & 0 & 20 & 0 or $10 ?$ \\
\hline 4 & 0 & 30 & 0 or $10 ?$ \\
\hline 5 & 10 & 0 & 0 or $10 ?$ \\
\hline 6 & 10 & 10 & 0 or $10 ?$ \\
\hline 7 & 10 & 20 & 0 or $10 ?$ \\
\hline
\end{tabular}




\begin{tabular}{|l|l|l|l|}
\hline 8 & 10 & 30 & 0 or $10 ?$ \\
\hline 9 & \multicolumn{3}{|c|}{ First Period } \\
\hline
\end{tabular}

\section{Strategy analysis results}

\section{Strategy Method (Round 6-10)}

Table A3. Summary of strategies used by HCA participants in the strategy method stage

\begin{tabular}{|c|c|c|c|c|c|c|c|}
\hline \multicolumn{2}{|c|}{ Treatment 1} & \multicolumn{2}{|c|}{ Treatment 2} & \multicolumn{2}{|c|}{ Treatment 3} & \multicolumn{2}{|c|}{ Treatment 4} \\
\hline Strategy & Freq. & Strategy & Freq. & Strategy & Freq. & Strategy & Freq. \\
\hline TFT & 1 & TFTc1d 1 & 1 & UC & 1 & $\mathrm{UC}$ & 4 \\
\hline TFTc1d2 & 11 & TFTc1d2 & 2 & GRIM & 4 & GRIM & 1 \\
\hline TFTc $2 \mathrm{~d} 2$ & 1 & TFTc $2 \mathrm{~d} 2$ & 1 & Trigger 2 & 2 & Trigger 1 & 1 \\
\hline TFTc2d3 & 3 & TFTc $2 d 3$ & 1 & TFT & 2 & Trigger 2 & 1 \\
\hline TFTc $3 \mathrm{~d} 2$ & 1 & C to All D & 1 & TFTc1d1 & 2 & TFT & 1 \\
\hline $\mathrm{C}$ to All D & 4 & DTFT & 1 & TFTc1d 2 & 4 & TFTc1d1 & 4 \\
\hline DTFT & 4 & DTFTc2d3 & 7 & TFTc $2 \mathrm{~d} 0$ & 1 & TFTc1d 2 & 6 \\
\hline DTFTc1d2 & 8 & UD & 31 & TFTc $2 \mathrm{~d} 3$ & 5 & TFTc $2 \mathrm{~d} 1$ & 1 \\
\hline DTFTc1d3 & 1 & Unclassified & 25 & TFTc $3 \mathrm{~d} 0$ & 1 & TFTc $2 \mathrm{~d} 2$ & 4 \\
\hline DTFTc2d 2 & 10 & Obs. & 70 & TFTc $3 \mathrm{~d} 2$ & 1 & TFTc $2 \mathrm{~d} 3$ & 4 \\
\hline DTFTc2d3 & 14 & & & $\mathrm{C}$ to All D & 2 & C to All D & 4 \\
\hline UD & 62 & & & DTFT & 2 & D to All C & 1 \\
\hline Unclassified & 20 & & & DTFTc1d3 & 1 & DTFT & 5 \\
\hline \multirow[t]{6}{*}{ Obs. } & 140 & & & DTFTc2d2 & 2 & DTFTc1d2 & 3 \\
\hline & & & & DTFTc2d3 & 2 & DTFTc2d2 & 2 \\
\hline & & & & DTFTc $3 \mathrm{~d} 2$ & 2 & DTFTc2d3 & 2 \\
\hline & & & & UD & 60 & UD & 32 \\
\hline & & & & Unclassified & 36 & Unclassified & 25 \\
\hline & & & & Obs. & 130 & Obs. & 101 \\
\hline
\end{tabular}


a: The unit of observation is the decision making in every round in the strategy-method stage.

b. The total number of observations is the number of HCA/LCA participants $\times$ the number of rounds under strategy method (Round 6 to 10).

Table A4. Summary of strategies used by LCA participants in the strategy method stage

\begin{tabular}{|c|c|c|c|c|c|c|c|}
\hline \multicolumn{2}{|c|}{ Treatment 1} & \multicolumn{2}{|c|}{ Treatment 2} & \multicolumn{2}{|c|}{ Treatment 3} & \multicolumn{2}{|c|}{ Treatment 4} \\
\hline Strategy & Freq. & Strategy & Freq. & Strategy & Freq. & Strategy & Freq. \\
\hline UC & 9 & $\mathrm{UC}$ & 5 & UC & 1 & $\mathrm{UC}$ & 2 \\
\hline GRIM & 2 & Trigger2 & 4 & GRIM & 2 & GRIM & 2 \\
\hline Trigger 1 & 1 & TFTc1d 1 & 5 & Trigger 2 & 2 & Trigger 2 & 1 \\
\hline Trigger 2 & 1 & TFTc1d 2 & 4 & TFT & 1 & TFTc1d 1 & 1 \\
\hline TFT & 2 & TFTc $2 \mathrm{~d} 3$ & 4 & TFTc1d 2 & 4 & TFTc1d 2 & 4 \\
\hline TFTc1d 1 & 1 & C to All D & 1 & TFTc1d3 & 1 & TFTc $2 \mathrm{~d} 2$ & 1 \\
\hline TFTc1d 2 & 6 & DTFT & 2 & TFTc2d 2 & 3 & TFTc2d 3 & 2 \\
\hline TFTc1d3 & 2 & DTFTc1d1 & 1 & TFTc2d3 & 3 & TFTc $3 \mathrm{~d} 0$ & 1 \\
\hline TFTc $2 \mathrm{~d} 3$ & 1 & DTFTc1d2 & 3 & C to All D & 1 & $\mathrm{C}$ to All D & 1 \\
\hline DTFT & 1 & DTFTc2d 2 & 1 & DTFTc0d2 & 1 & DTFT & 2 \\
\hline DTFTc1d2 & 2 & DTFTc2d3 & 11 & DTFTc1d2 & 1 & DTFTc1d2 & 5 \\
\hline DTFTc2d3 & 5 & UD & 50 & DTFTc2d3 & 6 & DTFTc1d3 & 3 \\
\hline DTFTc3d1 & 1 & Unclassified & 39 & UD & 45 & DTFTc2d2 & 1 \\
\hline DTFTc $3 \mathrm{~d} 2$ & 2 & Obs. & 130 & Unclassified & 19 & DTFTc2d3 & 4 \\
\hline UD & 37 & & & Obs. & 90 & UD & 40 \\
\hline Unclassified & 27 & & & & & Unclassified & 13 \\
\hline Obs. & 100 & & & & & Obs. & 83 \\
\hline
\end{tabular}

a: The unit of observation is the decision making in every round in the strategy-method stage. 
b: The total number of observations is the number of HCA/LCA participants $\times$ the number of rounds under strategy method (Round 6 to 10).

Table A5. Summary of frequency (\%) of strategy types in strategy method stage

\begin{tabular}{ccccccccc}
\hline & \multicolumn{3}{c}{ HCA participants } & \multicolumn{5}{c}{ LCA participants } \\
Strategy Types & $\mathrm{T} 1$ & $\mathrm{~T} 2$ & $\mathrm{~T} 3$ & $\mathrm{~T} 4$ & $\mathrm{~T} 1$ & $\mathrm{~T} 2$ & $\mathrm{~T} 3$ & $\mathrm{~T} 4$ \\
\hline Fully cooperative & 14.286 & 7.143 & 23.077 & 30.693 & 30 & 16.923 & 23.333 & 18.072 \\
UC & 0 & 0 & 0.769 & 3.960 & 9.000 & 3.846 & 1.111 & 2.410 \\
Lenient & 13.571 & 7.143 & 17.692 & 24.752 & 17 & 13.077 & 18.889 & 13.253 \\
Forgiving & 14.286 & 7.143 & 17.692 & 23.762 & 17 & 13.846 & 17.778 & 12.048 \\
Unforgiving & 0 & 0 & 4.615 & 2.970 & 4 & 3.077 & 4.444 & 3.614 \\
Partially cooperative & 5 & 20 & 13.077 & 12.871 & 15 & 9.231 & 6.667 & 9.639 \\
Fully non-cooperative & 80.714 & 72.857 & 63.846 & 56.436 & 55 & 73.846 & 70 & 72.289 \\
UD & 44.286 & 44.286 & 46.154 & 31.683 & 37 & 38.462 & 50 & 48.193 \\
Obs. & 140 & 70 & 130 & 101 & 100 & 130 & 90 & 83 \\
\hline
\end{tabular}

a: T1 for treatment 1 . T2 for treatment 2. T3 for treatment 3 . T4 for treatment 4.

b: The unit of observation is the decision making in every round in the strategy-method stage.

c: The total number of observations is the number of HCA/LCA participants $\times$ the number of rounds under strategy method (Round 6 to 10).

\section{Direct Response Method (Round 1- 5)}

We employ the strategy frequency estimation method, following Dal Bó and Fréchette (2011) and Fudenberg et al. (2012), to estimate the subjects' strategies in the first five rounds under direct-response method. ${ }^{3}$

${ }^{3}$ We thank Guillaume Fréchette for kindly providing the original code for strategy estimation. We also thank Maria Bigoni for kindly providing the modified code for strategy estimation. 
The method works on the history of play as follows. First, we generate the simulated action sequence by following the constructed strategy set which 35 simplified strategies considered in Table 1 in section 3.1. We compare a subject's actual action sequence against the simulated action sequence generated by a given strategy from constructed strategy set $s^{k}$. Then, strategy $s^{k}$ correctly matches the subject's action sequence $C$ times and does not match the sequence $E$ times. Therefore, the probability that player $i$ employs strategy $k$ is given by

$$
P_{i}\left(s^{k}\right)=\prod_{\text {round period }} \prod_{\prod^{C}(1-\beta)^{E}} \beta^{C}
$$

$\beta$ is the probability of correctly matching actions from the constructed strategy set and actions from the subjects. In each period, the subject plays according to the chosen strategy with probability $\beta \in\left(\frac{1}{2}, 1\right)$ and makes a mistake with probability (1- $\beta$ ). When $\beta$ is close to $\frac{1}{2}$, choices are almost random, and when it is close to 1 , choices are almost perfectly predicted. In addition, the likelihood function is given by

$$
\mathcal{L}(\beta, \phi)=\sum_{i \in \text { Subjects }} \ln \left(\sum_{k \in \text { Strategies }} \phi^{k} P_{i}\left(s^{k}\right)\right)
$$

$\phi^{k}$ is the frequency of strategy $k$.

For each treatment, we draw 100 random samples to calculate bootstrapped standard errors. Firstly, we generate random samples using the following two ways. For the analysis of the entire sample, we take all subjects in a given treatment and draw them at random with replacement until the random sample has as many subjects as in the treatment. For the analysis of the HCA/LCA participants subsample, we take all subjects from each subsample in a given treatment and draw them at random with replacement until the random sample has as many subjects as in the corresponding cognitive ability group in the treatment. Secondly, we estimate the strategy frequency for each random sample. Finally, we calculate the bootstrapped standard error.

Table A6. Estimation of strategies used in treatment 1(data from the direct-response-method stage) 
Strategy Freq. (\%) Bootstrapped p-value Strategy Freq. $(\%)$ Bootstrapped p-value

\begin{tabular}{|c|c|c|c|c|c|c|c|}
\hline \multicolumn{5}{|c|}{ SE } & \multicolumn{3}{|c|}{ SE } \\
\hline TFT & 3.506 & 0.017 & 0.019 & $\mathrm{UC}$ & 18.702 & 0.110 & 0.045 \\
\hline TFTc $2 d 3$ & 3.507 & 0.017 & 0.019 & TFTc $3 \mathrm{~d} 2$ & 7.377 & 0.056 & 0.093 \\
\hline TFTc $1 \mathrm{~d} 3$ & 3.506 & 0.017 & 0.019 & TFTc1d2 & 7.365 & 0.055 & 0.092 \\
\hline DTFT1 & 9.851 & 0.079 & 0.106 & DTFT2 & 62.004 & 0.242 & 0.005 \\
\hline DTFTc2d3 & 7.555 & 0.066 & 0.127 & DTFTc3d0 & 1.517 & 0.019 & 0.217 \\
\hline DTFTc1d3 & 7.498 & 0.066 & 0.128 & DTFTc1d0 & 1.517 & 0.019 & 0.217 \\
\hline DTFT & 7.442 & 0.066 & 0.130 & DTFTc2d0 & 1.517 & 0.019 & 0.217 \\
\hline DTFTc0d3 & 7.498 & 0.066 & 0.128 & $\gamma$ & 72.426 & 0.088 & 0.000 \\
\hline UD & 49.632 & 0.256 & 0.026 & $\beta$ & 79.911 & & \\
\hline$\gamma$ & 53.485 & 0.061 & 0.000 & & & & \\
\hline$\beta$ & 86.642 & & & & & & \\
\hline
\end{tabular}

a: The table reports the estimated frequency of each strategy in the population. We show the strategies with estimated frequency larger than $1 \%$.

b: The parameter $\gamma$ is used in estimation with $\beta=\frac{1}{1+\exp (-1 / \gamma)}$.

Table A7. Estimation of strategies used in treatment 2(data from the direct-response-method stage)

HCA participants $\quad$ LCA participants

Strategy Freq. (\%) Bootstrapped p-value Strategy $\quad$ Freq. $(\%)$ Bootstrapped p-value SE $\quad$ SE

\begin{tabular}{cccccccc}
\hline TFTc1d1 & 7.145 & 0.090 & 0.213 & UC & 5.4939 & 0.035 & 0.059 \\
DC alternative & 6.804 & 0.000 & 0.000 & Trigger2 & 6.7704 & 0.083 & 0.209 \\
DTFT & 39.426 & 0.199 & 0.024 & TFTc1d1 & 3.2768 & 0.037 & 0.188 \\
DTFTc1d1 & 7.202 & 0.078 & 0.179 & DTFTc2d2 & 21.673 & 0.127 & 0.043 \\
DTFTc1d3 & 9.890 & 0.061 & 0.053 & DTFTc3d1 & 1.9531 & 0.013 & 0.068
\end{tabular}




\begin{tabular}{cccccccc} 
DTFTc0d3 & 9.889 & 0.061 & 0.053 & DTFTc2d1 & 1.9531 & 0.013 & 0.068 \\
DTFTc2d3 & 9.824 & 0.061 & 0.054 & DTFTc0d1 & 1.9527 & 0.013 & 0.068 \\
UD & 9.817 & 0.061 & 0.054 & UD & 56.927 & 0.250 & 0.011 \\
$\gamma$ & 54.191 & 0.073 & 0.000 & $\gamma$ & 62.225 & 0.056 & 0.000 \\
$\beta$ & 86.358 & & & $\beta$ & 83.300 & & \\
\hline
\end{tabular}

a: The table reports the estimated frequency of each strategy in the population. We show the strategies with estimated frequency larger than $1 \%$.

b: The parameter $\gamma$ is used in estimation with $\beta=\frac{1}{1+\exp \left({ }^{-1} / \gamma\right)}$.

Table A8. Estimation of strategies used in treatment 3 (data from the direct-response-method stage)

\begin{tabular}{|c|c|c|c|c|c|c|c|}
\hline \multicolumn{4}{|c|}{ HCA participants } & \multicolumn{4}{|c|}{ LCA participants } \\
\hline Strategy & Freq. (\%) & Bootstrapped & p-value & Strategy & Freq. (\%) & Bootstrapped & p-value \\
\hline & & SE & & & & SE & \\
\hline Trigger1 & 20.565 & 0.113 & 0.034 & Trigger2 & 6.793 & 0.058 & 0.123 \\
\hline Trigger2 & 2.662 & 0.046 & 0.283 & TFT2 & 19.199 & 0.126 & 0.063 \\
\hline TFTc1d 1 & 18.788 & 0.065 & 0.002 & TFT1 & 5.474 & 0.071 & 0.222 \\
\hline TFT & 3.190 & 0.042 & 0.222 & DTFT1 & 5.152 & 0.072 & 0.236 \\
\hline DC alternative & 1.377 & 0.000 & 0.000 & C to All D & 4.511 & 0.049 & 0.180 \\
\hline DTFT & 8.446 & 0.100 & 0.199 & UD & 58.870 & 0.157 & 0.000 \\
\hline DTFTc $3 \mathrm{~d} 2$ & 2.663 & 0.024 & 0.129 & $\gamma$ & 56.506 & 0.095 & 0.000 \\
\hline DTFTc1d0 & 2.663 & 0.024 & 0.129 & $\beta$ & 85.442 & & \\
\hline DTFTc0d2 & 2.663 & 0.024 & 0.129 & & & & \\
\hline UD & 36.983 & 0.197 & 0.030 & & & & \\
\hline$\gamma$ & 68.832 & 0.092 & 0.000 & & & & \\
\hline$\beta$ & 81.043 & & & & & & \\
\hline
\end{tabular}


a: The table reports the estimated frequency of each strategy in the population. We show the strategies with estimated frequency larger than $1 \%$.

b: The parameter $\gamma$ is used in estimation with $\beta=\frac{1}{1+\exp (-1 / \gamma)}$.

Table A9. Estimation of strategies used in treatment 4 (data from the direct-response-method stage)

HCA participants

Strategy Freq. (\%) Bootstrapped p-value Strategy Freq. (\%) Bootstrapped p-value

\begin{tabular}{|c|c|c|c|c|c|c|c|}
\hline \multicolumn{5}{|c|}{ SE } & \multicolumn{3}{|c|}{ SE } \\
\hline UC & 12.983 & 0.092 & 0.078 & Trigger1 & 20.423 & 0.107 & 0.028 \\
\hline Grim & 6.879 & 0.057 & 0.114 & Trigger2 & 9.386 & 0.081 & 0.123 \\
\hline Trigger1 & 3.681 & 0.104 & 0.361 & TFT2 & 13.209 & 0.084 & 0.058 \\
\hline TFT1 & 13.838 & 0.075 & 0.032 & DTFT1 & 4.833 & 0.043 & 0.133 \\
\hline TFT2 & 5.116 & 0.068 & 0.224 & UD & 51.193 & 0.154 & 0.000 \\
\hline TFTc1d2 & 3.454 & 0.025 & 0.084 & $\gamma$ & 46.942 & 0.073 & 0.000 \\
\hline TFTc $3 \mathrm{~d} 2$ & 3.448 & 0.025 & 0.083 & $\beta$ & 89.381 & & \\
\hline UD & 50.601 & 0.199 & 0.005 & & & & \\
\hline$\gamma$ & 54.082 & 0.074 & 0.000 & & & & \\
\hline$\beta$ & 86.401 & & & & & & \\
\hline
\end{tabular}

a: The table reports the estimated frequency of each strategy in the population. We show the strategies with estimated frequency larger than $1 \%$.

b: The parameter $\gamma$ is used in estimation with $\beta=\frac{1}{1+\exp (-1 / \gamma)}$.

Table A10. Summary of estimated frequency (\%) of strategy types in direct response method by using SFEM

\begin{tabular}{ccccccccc}
\hline Strategy Types & \multicolumn{4}{c}{ HCA participants } & \multicolumn{4}{c}{ LCA participants } \\
& T1 & T2 & T3 & T4 & T1 & T2 & T3 & T4 \\
& & & & & & & \\
\hline Fully cooperative & 10.519 & 7.145 & 45.205 & 49.399 & 33.444 & 15.541 & 31.466 & 43.018
\end{tabular}




\begin{tabular}{ccccccccc} 
UC & 0 & 0 & 0 & 12.983 & 18.702 & 5.494 & 0 & 0 \\
Lenient & 7.013 & 7.145 & 42.015 & 29.537 & 14.742 & 10.047 & 31.466 & 43.018 \\
Forgiving & 10.519 & 7.145 & 21.978 & 25.856 & 14.742 & 3.277 & 24.673 & 13.209 \\
Unforgiving & 0 & 0 & 23.227 & 10.560 & 0 & 6.770 & 6.793 & 29.809 \\
Partially cooperative & 0 & 6.804 & 1.377 & 0 & 0 & 0 & 4.511 & 0 \\
Fully non-cooperative & 89.476 & 86.048 & 53.418 & 50.601 & 66.555 & 84.459 & 64.022 & 56.026 \\
UD & 49.632 & 9.817 & 36.983 & 50.601 & 0 & 56.927 & 58.870 & 51.193 \\
Obs. & 28 & 14 & 26 & 22 & 20 & 26 & 18 & 18 \\
\hline
\end{tabular}

a: T1 indicates treatment 1. T2 indicates treatment 2. T3 indicates treatment 3. T4 indicates treatment 4.

${ }^{\mathrm{b}}$ : The unit of observation is the number of HCA participants and LCA participants in each treatment.

\section{Regression results for figures}

Table A11. Odds ratio estimates of logistic regression of HCA dummy and demographic characteristics on first period cooperation and all periods cooperation in direct response method (Round 1 to 5) with robust standard error clustered by group
(1)
(2)
(3)
(4)
(5)
(6)
(7)
(8)

Direct Response Method

Direct Response Method

(Round 1 to 5)

(Round 1 to 5)

First Period Cooperation

VARIABLES

$\mathrm{T} 1$

T2

$\mathrm{T} 3$

$\mathrm{T} 4$

All Period Cooperation

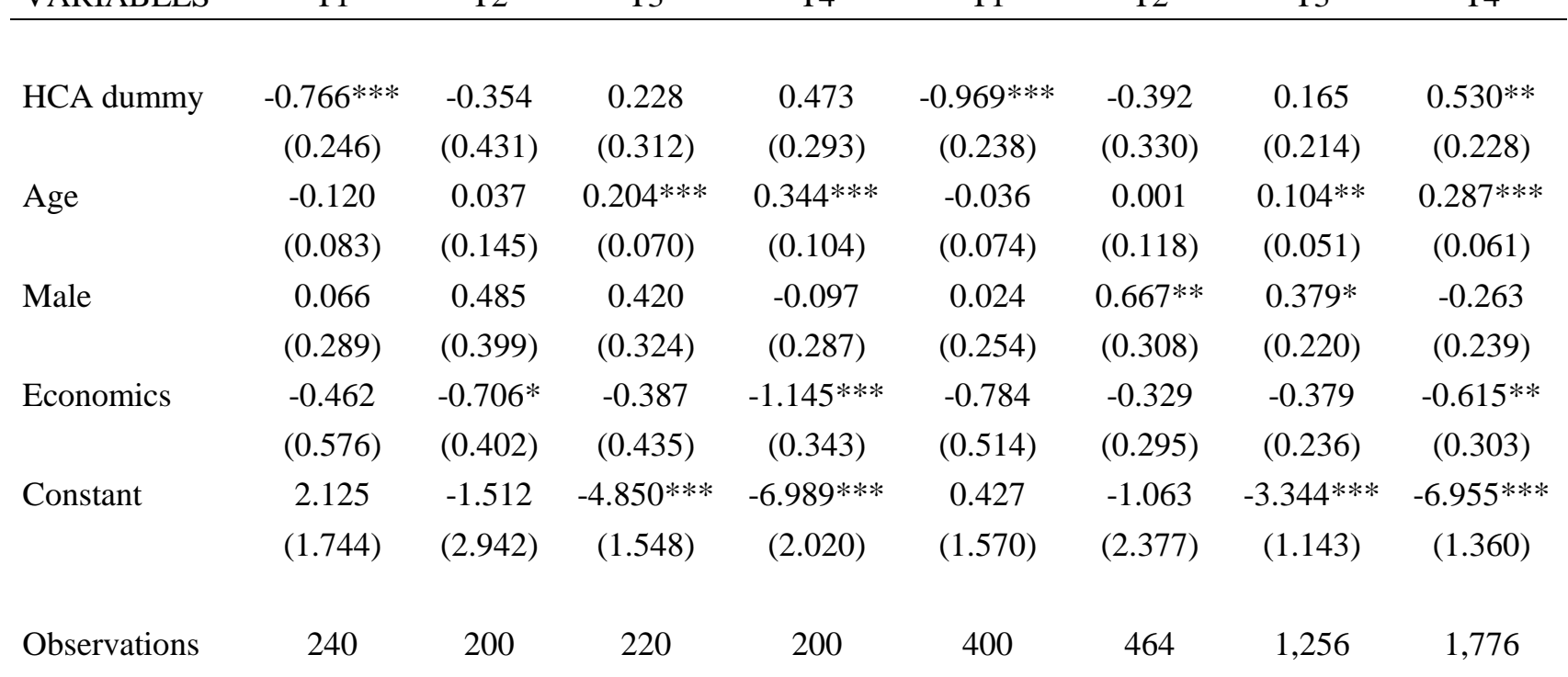




\begin{tabular}{lcccccccc} 
Clusters & 60 & 50 & 55 & 50 & 60 & 50 & 55 & 50 \\
Wald chi2 & 12.332 & 5.467 & 21.417 & 22.516 & 19.362 & 7.568 & 24.605 & 35.750 \\
Prob > chi2 & 0.015 & 0.243 & 0.000 & 0.000 & 0.001 & 0.109 & 0.000 & 0.000 \\
Pseudo R2 & 0.030 & 0.022 & 0.055 & 0.091 & 0.043 & 0.017 & 0.025 & 0.056 \\
\hline \multicolumn{7}{c}{ Predicted first period cooperation rate } & \multicolumn{2}{c}{ Predicted all period cooperation rate } \\
\hline HCA & 0.241 & 0.256 & 0.448 & 0.489 & 0.209 & 0.228 & 0.297 & 0.276 \\
participants & $(0.032)$ & $(0.061)$ & $(0.047)$ & $(0.050))$ & $(0.029)$ & $(0.049)$ & $(0.037)$ & $(0.039)$ \\
LCA & 0.404 & 0.327 & 0.397 & 0.387 & 0.409 & 0.302 & 0.264 & 0.187 \\
participants & $(0.044)$ & $(0.043)$ & $(0.052)$ & $(0.042)$ & $(0.052)$ & $(0.039)$ & $(0.034)$ & $(0.033)$
\end{tabular}

a: HCA dummy $=1$ for HCA participants and 0 for LCA participants. Male $=1$ for male and 0 for female.

Economics $=1$ for students from economics and management major and 0 for otherwise. ${ }^{\text {b}}$ : The unit of observation is the decision making in period 1 in every round. The total number of observations is the number of subjects $\times$ number of rounds. ${ }^{c}$ : The robust standard errors cluster by group are in parentheses. ${ }^{* * *} \mathrm{p}<0.01,{ }^{* *} \mathrm{p}$ $<0.05$, and $* \mathrm{p}<0.1$

Table A12. Odds ratio estimates of logistic regression of HCA dummy and demographic characteristics on first period cooperation and all periods cooperation in strategy method (Round 6 to 10) with robust standard error clustered by group

\begin{tabular}{|c|c|c|c|c|c|c|c|c|}
\hline \multirow[b]{3}{*}{ VARIABLES } & (1) & (2) & (3) & (4) & (5) & (6) & (7) & (8) \\
\hline & \multicolumn{4}{|c|}{$\begin{array}{l}\text { Strategy Method } \\
\text { (Round } 6 \text { to 10) }\end{array}$} & \multicolumn{4}{|c|}{$\begin{array}{l}\text { Strategy Method } \\
\text { (Round } 6 \text { to } 10 \text { ) }\end{array}$} \\
\hline & $\mathrm{T} 1$ & $\mathrm{~T} 2$ & $\mathrm{~T} 3$ & $\mathrm{~T} 4$ & $\mathrm{~T} 1$ & $\mathrm{~T} 2$ & $\mathrm{~T} 3$ & $\mathrm{~T} 4$ \\
\hline HCA dummy & $\begin{array}{c}-0.944 * * * \\
(0.349)\end{array}$ & $\begin{array}{l}-0.615 \\
(0.385)\end{array}$ & $\begin{array}{c}0.288 \\
(0.295)\end{array}$ & $\begin{array}{c}1.045^{* * *} \\
(0.327)\end{array}$ & $\begin{array}{c}-1.239 * * * \\
(0.355)\end{array}$ & $\begin{array}{l}-0.482 \\
(0.517)\end{array}$ & $\begin{array}{c}0.141 \\
(0.277)\end{array}$ & $\begin{array}{l}-0.363 \\
(0.473)\end{array}$ \\
\hline Age & $\begin{array}{l}-0.057 \\
(0.092)\end{array}$ & $\begin{array}{c}0.101 \\
(0.159)\end{array}$ & $\begin{array}{l}0.100 \\
(0.076)\end{array}$ & $\begin{array}{l}0.156^{*} \\
(0.090)\end{array}$ & $\begin{array}{l}-0.053 \\
(0.087)\end{array}$ & $\begin{array}{c}0.017 \\
(0.139)\end{array}$ & $\begin{array}{c}0.320 * * * \\
(0.078)\end{array}$ & $\begin{array}{c}0.476^{* * *} \\
(0.129)\end{array}$ \\
\hline Male & $\begin{array}{c}0.281 \\
(0.361)\end{array}$ & $\begin{array}{l}0.715^{*} \\
(0.414)\end{array}$ & $\begin{array}{c}0.553 \\
(0.358)\end{array}$ & $\begin{array}{c}0.752 * * \\
(0.381)\end{array}$ & $\begin{array}{c}0.363 \\
(0.338)\end{array}$ & $\begin{array}{c}0.880 * * \\
(0.404)\end{array}$ & $\begin{array}{c}0.167 \\
(0.400)\end{array}$ & $\begin{array}{l}-0.567 \\
(0.417)\end{array}$ \\
\hline Economics & $\begin{array}{l}-2.162^{*} \\
(1.110)\end{array}$ & $\begin{array}{c}0.158 \\
(0.381)\end{array}$ & $\begin{array}{l}-0.480 \\
(0.427)\end{array}$ & $\begin{array}{c}-0.869 * * \\
(0.381)\end{array}$ & $\begin{array}{c}-2.524 * * \\
(1.150)\end{array}$ & $\begin{array}{l}-0.007 \\
(0.335)\end{array}$ & $\begin{array}{c}0.522 \\
(0.641)\end{array}$ & $\begin{array}{l}-0.132 \\
(0.451)\end{array}$ \\
\hline Constant & $\begin{array}{c}0.570 \\
(1.897)\end{array}$ & $\begin{array}{l}-3.447 \\
(3.210)\end{array}$ & $\begin{array}{c}-3.306^{* *} \\
(1.636)\end{array}$ & $\begin{array}{c}-4.642 * * \\
(1.822)\end{array}$ & $\begin{array}{c}0.441 \\
(1.823)\end{array}$ & $\begin{array}{l}-2.273 \\
(2.775)\end{array}$ & $\begin{array}{c}-9.072 * * * \\
(1.719)\end{array}$ & $\begin{array}{c}-11.239 * * * \\
(2.511)\end{array}$ \\
\hline Observations & 240 & 200 & 220 & 184 & 320 & 532 & 1,232 & 1,792 \\
\hline Clusters & 60 & 50 & 55 & 46 & 60 & 50 & 55 & 46 \\
\hline Wald chi2 & 11.212 & 3.881 & 9.779 & 22.027 & 15.983 & 7.161 & 19.586 & 14.797 \\
\hline Prob > chi 2 & 0.024 & 0.422 & 0.044 & 0.000 & 0.003 & 0.128 & 0.001 & 0.005 \\
\hline Pseudo R2 & 0.060 & 0.017 & 0.041 & 0.091 & 0.089 & 0.020 & 0.048 & 0.076 \\
\hline
\end{tabular}




\begin{tabular}{lcccccccc}
\hline HCA & 0.182 & 0.162 & 0.336 & 0.431 & 0.140 & 0.123 & 0.112 & 0.089 \\
participants & $(0.035)$ & $(0.039)$ & $(0.039)$ & $(0.047)$ & $(0.027)$ & $(0.033)$ & $(0.022)$ & $(0.020)$ \\
LCA & 0.358 & 0.260 & 0.278 & 0.224 & 0.352 & 0.183 & 0.099 & 0.121 \\
participants & $(0.051)$ & $(0.037)$ & $(0.045)$ & $(0.042)$ & $(0.057)$ & $(0.041)$ & $(0.025)$ & $(0.041)$
\end{tabular}

a: HCA dummy $=1$ for subjects belong to HCA participants and 0 for LCA participants. Male $=1$ for male and 0 for female. Economics $=1$ for students from economics and management major and 0 for otherwise. ${ }^{\text {b: }}$ The unit of observation is the decision making in period 1 in every round. The total number of observations is the number of subjects $\times$ number of rounds. ${ }^{c}$ : The robust standard errors cluster by group are in parentheses. $* * * \mathrm{p}<0.01,{ }^{* *} \mathrm{p}$ $<0.05$, and $* \mathrm{p}<0.1$

Table A13. Odds ratio estimates of logistic regression of HCA dummy and demographic characteristics on first period cooperation and all periods cooperation in strategy method (Simulation) with robust standard error clustered by group

\begin{tabular}{|c|c|c|c|c|c|c|c|c|}
\hline \multirow[b]{4}{*}{ VARIABLES } & (1) & (2) & (3) & (4) & (5) & (6) & (7) & (8) \\
\hline & \multicolumn{4}{|c|}{$\begin{array}{l}\text { Strategy Method } \\
\quad \text { (Simulation) }\end{array}$} & \multicolumn{4}{|c|}{$\begin{array}{l}\text { Strategy Method } \\
\text { (Simulation) }\end{array}$} \\
\hline & \multicolumn{4}{|c|}{ First period cooperation } & \multicolumn{4}{|c|}{ All period cooperation } \\
\hline & $\mathrm{T} 1$ & $\mathrm{~T} 2$ & $\mathrm{~T} 3$ & $\mathrm{~T} 4$ & $\mathrm{~T} 1$ & $\mathrm{~T} 2$ & $\mathrm{~T} 3$ & $\mathrm{~T} 4$ \\
\hline HCA dummy & $\begin{array}{c}-0.944 * * * \\
(0.016)\end{array}$ & $\begin{array}{c}-0.112 * * * \\
(0.027)\end{array}$ & $\begin{array}{l}0.021^{*} \\
(0.013)\end{array}$ & $\begin{array}{c}0.768 * * * \\
(0.009)\end{array}$ & $\begin{array}{c}-0.888 * * * \\
(0.016)\end{array}$ & $\begin{array}{c}-0.263 * * * \\
(0.030)\end{array}$ & $\begin{array}{c}0.003 \\
(0.014)\end{array}$ & $\begin{array}{c}0.083^{* * * *} \\
(0.010)\end{array}$ \\
\hline Age & $\begin{array}{c}-0.057 * * * \\
(0.004)\end{array}$ & $\begin{array}{c}0.077 * * * \\
(0.008)\end{array}$ & $\begin{array}{c}0.085^{* * * *} \\
(0.003)\end{array}$ & $\begin{array}{l}-0.000 \\
(0.004)\end{array}$ & $\begin{array}{c}-0.048^{* * *} \\
(0.004)\end{array}$ & $\begin{array}{c}0.109 * * * \\
(0.007)\end{array}$ & $\begin{array}{c}0.161 * * * \\
(0.003)\end{array}$ & $\begin{array}{c}-0.018 * * * \\
(0.005)\end{array}$ \\
\hline Male & $\begin{array}{c}0.281 * * * \\
(0.016)\end{array}$ & $\begin{array}{c}0.115^{* * * *} \\
(0.028)\end{array}$ & $\begin{array}{c}1.004 * * * \\
(0.013)\end{array}$ & $\begin{array}{c}0.278 * * * \\
(0.010)\end{array}$ & $\begin{array}{c}0.263 * * * \\
(0.015)\end{array}$ & $\begin{array}{c}0.448 * * * \\
(0.028)\end{array}$ & $\begin{array}{c}0.581 * * * \\
(0.013)\end{array}$ & $\begin{array}{c}-0.300 * * * \\
(0.011)\end{array}$ \\
\hline Economics & $\begin{array}{c}-2.162 * * * \\
(0.050)\end{array}$ & $\begin{array}{c}-0.259 * * * \\
(0.026)\end{array}$ & $\begin{array}{c}-0.061 * * * \\
(0.017)\end{array}$ & $\begin{array}{c}-0.989 * * * \\
(0.011)\end{array}$ & $\begin{array}{c}-2.495^{* * *} \\
(0.051)\end{array}$ & $\begin{array}{c}-0.305 * * * \\
(0.027)\end{array}$ & $\begin{array}{c}0.284 * * * \\
(0.020)\end{array}$ & $\begin{array}{c}-0.807 * * * \\
(0.014)\end{array}$ \\
\hline Constant & $\begin{array}{c}0.570 * * * \\
(0.083)\end{array}$ & $\begin{array}{c}-2.783 * * * \\
(0.155)\end{array}$ & $\begin{array}{c}-2.743 * * * \\
(0.065)\end{array}$ & $\begin{array}{c}-0.939 * * * \\
(0.074)\end{array}$ & $\begin{array}{c}0.284 * * * \\
(0.079)\end{array}$ & $\begin{array}{c}-3.806 * * * \\
(0.153)\end{array}$ & $\begin{array}{c}-5.119 * * * \\
(0.076)\end{array}$ & $\begin{array}{c}-1.076 * * * \\
(0.094)\end{array}$ \\
\hline Observations & 109,200 & 56,200 & 116,700 & 241,640 & 145,600 & 148,100 & 460,560 & $2,773,568$ \\
\hline Clusters & 27300 & 14050 & 29175 & 60410 & 27300 & 14050 & 29175 & 60410 \\
\hline Wald chi2 & 5768.71 & 309.56 & 8801.68 & 20508.26 & 5643.65 & 785.36 & 4555.24 & 3811.93 \\
\hline Prob > chi2 & 0.000 & 0.000 & 0.000 & 0.000 & 0.000 & 0.000 & 0.000 & 0.000 \\
\hline \multirow[t]{2}{*}{ Pseudo R2 } & 0.060 & 0.004 & 0.053 & 0.056 & 0.062 & 0.0097 & 0.028 & 0.017 \\
\hline & \multicolumn{4}{|c|}{ Predicted first period cooperation rate } & \multicolumn{4}{|c|}{ Predicted all period cooperation rate } \\
\hline $\begin{array}{l}\text { HCA } \\
\text { participants }\end{array}$ & $\begin{array}{c}0.182 \\
(0.002)\end{array}$ & $\begin{array}{c}0.205 \\
(0.003)\end{array}$ & $\begin{array}{c}0.423 \\
(0.002)\end{array}$ & $\begin{array}{c}0.436 \\
(0.001)\end{array}$ & $\begin{array}{c}0.173 \\
(0.002)\end{array}$ & $\begin{array}{c}0.150 \\
(0.003)\end{array}$ & $\begin{array}{c}0.215 \\
(0.002)\end{array}$ & $\begin{array}{c}0.144 \\
(0.001)\end{array}$ \\
\hline $\begin{array}{l}\text { LCA } \\
\text { participants }\end{array}$ & $\begin{array}{c}0.358 \\
(0.002)\end{array}$ & $\begin{array}{c}0.224 \\
(0.002)\end{array}$ & $\begin{array}{c}0.418 \\
(0.002)\end{array}$ & $\begin{array}{c}0.271 \\
(0.001)\end{array}$ & $\begin{array}{c}0.332 \\
(0.002)\end{array}$ & $\begin{array}{c}0.187 \\
(0.002)\end{array}$ & $\begin{array}{c}0.215 \\
(0.002)\end{array}$ & $\begin{array}{c}0.154 \\
(0.001)\end{array}$ \\
\hline
\end{tabular}


a: HCA dummy $=1$ for HCA participants and 0 for LCA participants. Male $=1$ for male and 0 for female.

Economics $=1$ for students from economics and management major and 0 for otherwise. ${ }^{\text {b: }}$ The unit of observation is the decision making in period 1 in every round. The total number of observations is the number of subjects $\times$ number of rounds. ${ }^{c}$ : The robust standard errors cluster by group are in parentheses. $* * * p<0.01, * * p$ $<0.05$, and $* \mathrm{p}<0.1$

Table A14. Odds ratio estimates of logistic regression of HCA dummy and demographic characteristics on the fully cooperative strategy in strategy method stage, with robust standard error
(1)
(2)
(3)
(4)

Fully cooperative strategy dummy

VARIABLES

$\mathrm{T} 1$

$\mathrm{T} 2$

$\mathrm{T} 3$

$\mathrm{T} 4$

\begin{tabular}{lcccc} 
HCA dummy & $-1.055^{* * *}$ & $-1.202^{*}$ & -0.308 & $0.880^{* *}$ \\
Age & $(0.341)$ & $(0.624)$ & $(0.364)$ & $(0.386)$ \\
& 0.012 & -0.123 & 0.125 & $0.310^{* * *}$ \\
Male & $(0.093)$ & $(0.198)$ & $(0.085)$ & $(0.109)$ \\
& 0.585 & 0.672 & $0.939^{* *}$ & 0.475 \\
Economics & $(0.370)$ & $(0.467)$ & $(0.393)$ & $(0.438)$ \\
& $-1.902^{*}$ & $0.790^{*}$ & -0.502 & -0.651 \\
Constant & $(1.085)$ & $(0.435)$ & $(0.528)$ & $(0.450)$ \\
& -1.286 & 0.362 & $-4.157^{* *}$ & $-7.956^{* * *}$ \\
& $(1.929)$ & $(3.916)$ & $(1.832)$ & $(2.104)$ \\
Observations & & & & 184 \\
Wald chi2 & 240 & 200 & 220 & 19.406 \\
Prob > chi2 & 13.573 & 9.315 & 11.103 & 0.001 \\
Pseudo R2 & 0.009 & 0.054 & 0.025 & 0.094 \\
\hline & 0.069 & 0.064 & 0.058 & \\
\hline HCA participants & & Predicted Frequency & $0.322(0.046)$ \\
LCA participants & $0.139(0.029)$ & $0.064(0.031)$ & $0.213(0.035)$ & $0.175(0.040)$
\end{tabular}

a: Fully cooperative strategy dummy $=1$ for fully cooperative strategy and 0 for other strategies. HCA dummy $=1$ for HCA participants and 0 for LCA participants. Male $=1$ for male and 0 for female. Economics $=1$ for students from economics and management major and 0 for otherwise. ${ }^{b}$ : The unit of observation is the elicited strategy in every round. The total number of observations is the number of subjects $\times$ number of rounds. ${ }^{c}$ : The robust standard errors are in parentheses. $* * * \mathrm{p}<0.01, * * \mathrm{p}<0.05$, and $* \mathrm{p}<0.1$

Table A15. Odds ratio estimates of logistic regression of HCA dummy and demographic characteristics on the forgiving strategy in strategy method stage, with robust standard error
(1)
(2)
(3)

(4)

Forgiving strategy dummy 


\begin{tabular}{lcccc} 
HCA dummy & -0.266 & -1.074 & -0.192 & $0.970^{* *}$ \\
Age & $(0.369)$ & $(0.661)$ & $(0.399)$ & $(0.426)$ \\
& 0.047 & -0.169 & 0.119 & 0.150 \\
Male & $(0.089)$ & $(0.232)$ & $(0.092)$ & $(0.121)$ \\
& 0.216 & $1.015^{* *}$ & 0.518 & 0.424 \\
Economics & $(0.383)$ & $(0.508)$ & $(0.422)$ & $(0.491)$ \\
& N/A & $1.165^{* *}$ & -0.568 & -0.616 \\
Constant & & $(0.467)$ & $(0.593)$ & $(0.513)$ \\
& -2.566 & 0.710 & $-4.138^{* *}$ & $-5.180^{* *}$ \\
& $(1.845)$ & $(4.560)$ & $(1.971)$ & $(2.283)$ \\
Observations & & & & \\
Wald chi2 & 220 & 200 & 220 & 184 \\
Prob > chi2 & 1.099 & 11.844 & 5.835 & 10.386 \\
Pseudo R2 & 0.777 & 0.019 & 0.212 & 0.034 \\
& 0.006 & 0.094 & 0.033 & 0.058 \\
\hline HCA participants & & Predicted Frequency & \\
LCA participants & $0.153(0.032)$ & $0.061(0.030)$ & $0.167(0.033)$ & $0.249(0.044)$ \\
& $0.190(0.042)$ & $0.151(0.033)$ & $0.194(0.044)$ & $0.114(0.034)$
\end{tabular}

${ }^{\mathrm{a}}$ : Forgiving strategy dummy $=1$ for forgiving strategy and 0 for other strategies. HCA dummy $=1$ for HCA participants and 0 for LCA participants. Male $=1$ for male and 0 for female. Economics $=1$ for students from economics and management major and 0 for otherwise. ${ }^{\text {b: }}$ The unit of observation is the elicited strategy in every round. The total number of observations is the number of subjects $\times$ number of rounds. ${ }^{c}$ : The robust standard errors are in parentheses. $* * * p<0.01, * * \mathrm{p}<0.05$, and $* \mathrm{p}<0.1$

Table A16. Odds ratio estimates of logistic regression of HCA dummy and demographic characteristics on the lenient strategy in strategy method stage, with robust standard error
(1)
(2)

Lenient strategy dummy

\section{VARIABLES}

$\mathrm{T} 1$

$\mathrm{T} 2$

T3

$\mathrm{T} 4$

$\begin{array}{lcccc}\text { HCA dummy } & -0.345 & -0.677 & -0.332 & 0.898^{* *} \\ & (0.375) & (0.644) & (0.404) & (0.416) \\ \text { Age } & 0.042 & -0.157 & 0.080 & 0.157 \\ & (0.092) & (0.209) & (0.099) & (0.117) \\ \text { Male } & 0.449 & 0.276 & 0.757^{*} & 0.379 \\ & (0.405) & (0.516) & (0.441) & (0.469) \\ \text { Economics } & \mathrm{N} / \mathrm{A} & 0.596 & -0.577 & -0.520 \\ & & (0.475) & (0.588) & (0.495) \\ \text { Constant } & -2.597 & 0.906 & -3.381 & -5.186^{* *}\end{array}$




\begin{tabular}{lcccc} 
Observations & 220 & 200 & 220 & 184 \\
Wald chi2 & 2.328 & 4.949 & 6.649 & 9.564 \\
Prob > chi2 & 0.507 & 0.293 & 0.156 & 0.048 \\
Pseudo R2 & 0.013 & 0.032 & 0.040 & 0.052 \\
\hline
\end{tabular}

Predicted Frequency

\begin{tabular}{lllll}
\hline HCA participants & $0.144(0.031)$ & $0.072(0.035)$ & $0.164(0.033)$ & $0.258(0.045)$ \\
LCA participants & $0.192(0.042)$ & $0.131(0.032)$ & $0.212(0.047)$ & $0.127(0.036)$
\end{tabular}

${ }^{a}$ : Lenient strategy dummy $=1$ for lenient strategy and 0 for other strategies. HCA dummy $=1$ for HCA participants and 0 for LCA participants. Male $=1$ for male and 0 for female. Economics $=1$ for students from economics and management major and 0 for otherwise. ${ }^{\text {b: }}$ The unit of observation is the elicited strategy in every round. The total number of observations is the number of subjects $\times$ number of rounds. ${ }^{c}$ : The robust standard errors are in parentheses. ${ }^{* * *} \mathrm{p}<0.01,{ }^{* *} \mathrm{p}<0.05$, and $* \mathrm{p}<0.1$

Table A17. Odds ratio estimates of logistic regression of treatment dummy and demographic characteristics on cooperation in period 1 and all periods among HCA participants and LCA participants in direct response method (Round 1 to 5) with robust standard error clustered by group; and the fully cooperative strategy among HCA participants and LCA participants in strategy method (Round 6 to 10) with robust standard error

\begin{tabular}{lcccccc}
\hline & $(1)$ & $(2)$ & $(1)$ & $(2)$ & $(3)$ & $(4)$ \\
& HCA & LCA & HCA & LCA & HCA & LCA \\
& Direct & Direct & Direct & Direct & Strategy & Strategy \\
& Response & Response & Response & Response & Method & Method \\
& Method & Method & Method & Method & (Round 6 to & (Round 6 to \\
& (Round 1 to 5) & (Round 1 to 5) & (Round 1 to 5) & (Round 1 to 5) & 10 ) & $10)$ \\
& Cooperation & Cooperation & Cooperation & Cooperation & Fully & Fully \\
& Period 1 & Period 1 & All periods & All periods & cooperative & cooperative \\
& & & & & strategy & strategy \\
\hline (Default: & & & & & \\
Treatment 1) & & & & & \\
Treatment 2 & 0.453 & 0.114 & $0.576^{*}$ & -0.209 & -0.645 & -0.419 \\
Treatment 3 & $(0.327)$ & $(0.287)$ & $(0.329)$ & $(0.287)$ & $(0.533)$ & $(0.349)$ \\
& $1.079 * * *$ & 0.090 & $0.633^{* *}$ & $-0.584 * *$ & $0.630^{*}$ & -0.227 \\
Treatment 4 & $(0.271)$ & $(0.298)$ & $(0.251)$ & $(0.271)$ & $(0.327)$ & $(0.336)$ \\
& $1.326 * * *$ & 0.326 & $0.635^{* *}$ & $-0.970^{* * *}$ & $1.361 * * *$ & $-0.779 *$ \\
Age & $(0.282)$ & $(0.296)$ & $(0.272)$ & $(0.347)$ & $(0.353)$ & $(0.408)$ \\
& 0.074 & $0.249 * * *$ & $0.168^{* * *}$ & $0.130^{* *}$ & $0.163 * * *$ & 0.034 \\
Male & $(0.050)$ & $(0.084)$ & $(0.045)$ & $(0.066)$ & $(0.059)$ & $(0.092)$ \\
& -0.041 & $0.391 *$ & -0.126 & $0.455^{*}$ & 0.439 & $0.952 * * *$ \\
Economics & $(0.208)$ & $(0.227)$ & $(0.175)$ & $(0.240)$ & $(0.286)$ & $(0.281)$ \\
& $-0.748 * * *$ & $-0.747 * *$ & $-0.437 *$ & $-0.482 * *$ & -0.499 & -0.146
\end{tabular}




$\begin{array}{lcccccc} & (0.259) & (0.297) & (0.256) & (0.228) & (0.351) & (0.316) \\ \text { Constant } & -2.639 * * & -5.798 * * * & -4.769 * * * & -3.305^{* *} & -5.496 * * * & -2.075 \\ & (1.104) & (1.759) & (0.993) & (1.412) & (1.311) & (1.957) \\ \text { Observations } & 450 & 410 & 2,124 & 1,772 & 441 & 403 \\ \text { Clusters } & 201 & 199 & 201 & 199 & & \\ \text { Wald chi2 } & 37.035 & 24.096 & 32.290 & 30.014 & 27.068 & 19.034 \\ \text { Prob > chi2 } & 0.000 & 0.001 & 0.000 & 0.000 & 0.000 & 0.004 \\ \text { Pseudo R2 } & 0.052 & 0.052 & 0.030 & 0.040 & 0.077 & 0.050\end{array}$

\begin{tabular}{lcccccc}
\hline \multicolumn{7}{c}{ Predicted Frequency } \\
\hline T1 & $0.223(0.032)$ & $0.339(0.041)$ & $0.182(0.027)$ & $0.367(0.048)$ & $0.132(0.028)$ & $0.277(0.044)$ \\
T2 & $0.309(0.054)$ & $0.363(0.044)$ & $0.280(0.053)$ & $0.321(0.042)$ & $0.074(0.032)$ & $0.204(0.039)$ \\
T3 & $0.451(0.049)$ & $0.358(0.049)$ & $0.291(0.036)$ & $0.248(0.033)$ & $0.218(0.035)$ & $0.236(0.044)$ \\
T4 & $0.511(0.049)$ & $0.409(0.048)$ & $0.292(0.040)$ & $0.184(0.037)$ & $0.360(0.050)$ & $0.154(0.040)$ \\
\hline & Prob > chi2 & Prob > chi2 & Prob > chi2 & Prob > chi2 & Prob > chi2 & Prob > chi2 \\
\hline T1=T2 & 0.166 & 0.693 & 0.080 & 0.467 & 0.226 & 0.230 \\
T1=T3 & 0.000 & 0.762 & 0.012 & 0.031 & 0.054 & 0.499 \\
T1=T4 & 0.000 & 0.271 & 0.020 & 0.005 & 0.000 & 0.056 \\
T2=T3 & 0.058 & 0.940 & 0.861 & 0.159 & 0.014 & 0.594 \\
T2=T4 & 0.008 & 0.490 & 0.859 & 0.025 & 0.000 & 0.385 \\
T3=T4 & 0.401 & 0.470 & 0.993 & 0.237 & 0.025 & 0.194 \\
& & & & & &
\end{tabular}

a: Treatment 1 dummy $=1$ for treatment 1 and 0 for others. Treatment 2 dummy $=1$ for treatment 2 and 0 for others. Treatment 3 dummy $=1$ for treatment 3 and 0 for others. Treatment 4 dummy $=1$ for treatment 4 and 0 for others. The default treatment is treatment 1 . Male $=1$ for male and 0 for female. Economics $=1$ for students from economics and management major and 0 for otherwise. ${ }^{b}$ : The unit of observation is the decision making in all periods in every round. The total number of observations is the number of subjects $\times$ number of rounds $x$ number of periods. ${ }^{c}$ : The robust standard errors cluster by group are in parentheses. $* * * p<0.01, * * p<0.05$, and $* \mathrm{p}<0.1$

\section{E. Analyses of experimental results unconditional on personal characteristics}

Table A18. Odds ratio estimates of logistic regression of HCA dummy on first period cooperation and all periods cooperation in direct response method (Round 1 to 5) with robust standard error clustered by group
(1)
(2)
(3)
(4)
(5)
(6)
(7)

Direct Response Method

Direct Response Method (Round 1 to 5) (Round 1 to 5)

First Period Cooperation All Period Cooperation

\begin{tabular}{ccccccccc} 
VARIABLES & $\mathrm{T} 1$ & $\mathrm{~T} 2$ & $\mathrm{~T} 3$ & $\mathrm{~T} 4$ & $\mathrm{~T} 1$ & $\mathrm{~T} 2$ & $\mathrm{~T} 3$ & $\mathrm{~T} 4$ \\
\hline & & & & & & & & \\
HCA dummy & $-0.732 * * *$ & 0.000 & 0.345 & 0.214 & $-0.932 * * *$ & 0.010 & 0.293 & $0.452 *$
\end{tabular}




\begin{tabular}{lcccccccc} 
& $(0.235)$ & $(0.342)$ & $(0.292)$ & $(0.276)$ & $(0.229)$ & $(0.308)$ & $(0.188)$ & $(0.244)$ \\
Constant & $-0.405^{* *}$ & $-0.847 * * *$ & $-0.499 * *$ & $-0.359^{*}$ & $-0.386^{*}$ & $-0.979 * * *$ & $-1.104 * * *$ & $-1.447 * * *$ \\
& $(0.177)$ & $(0.193)$ & $(0.222)$ & $(0.207)$ & $(0.208)$ & $(0.177)$ & $(0.169)$ & $(0.227)$ \\
& & & & & & & \\
Observations & 240 & 200 & 220 & 200 & 400 & 464 & 1,256 & 1,776 \\
Clusters & 60.000 & 50.000 & 55.000 & 50.000 & 60.000 & 50.000 & 55.000 & 50.000 \\
Wald chi2 & 9.702 & 0.000 & 1.393 & 0.598 & 16.590 & 0.001 & 2.438 & 3.421 \\
Prob > chi2 & 0.002 & 1.000 & 0.238 & 0.439 & 0.000 & 0.974 & 0.118 & 0.064 \\
Pseudo R2 & 0.023 & 0.000 & 0.005 & 0.002 & 0.036 & 0.000 & 0.003 & 0.008 \\
\hline \multicolumn{7}{c}{ First period cooperation rate } \\
HCA & 0.243 & 0.300 & 0.462 & 0.464 & 0.211 & 0.275 & 0.308 & 0.270 \\
participants & $(0.036)$ & $(0.055)$ & $(0.044)$ & $(0.048)$ & $(0.027)$ & $(0.035)$ & $(0.017)$ & $(0.014)$ \\
LCA & 0.400 & 0.300 & 0.378 & 0.411 & 0.405 & 0.273 & 0.249 & 0.190 \\
participants & $(0.049)$ & $(0.040)$ & $(0.051)$ & $(0.052)$ & $(0.038)$ & $(0.026)$ & $(0.019)$ & $(0.014)$
\end{tabular}

a: HCA dummy $=1$ for HCA participants and 0 for LCA participants. Male $=1$ for male and 0 for female.

Economics $=1$ for students from economics and management major and 0 for otherwise. ${ }^{b}$ : The unit of observation is the decision making in period 1 in every round. The total number of observations is the number of subjects $\times$ number of rounds. ${ }^{c}$ : The robust standard errors cluster by group are in parentheses. ${ }^{* *} \mathrm{p}<0.01,{ }^{* *} \mathrm{p}$ $<0.05$, and $* \mathrm{p}<0.1$

Table A19. Odds ratio estimates of logistic regression of HCA dummy on first period cooperation and all periods cooperation in strategy method (Round 6 to 10) with robust standard error clustered by group

\begin{tabular}{|c|c|c|c|c|c|c|c|c|}
\hline \multirow[b]{3}{*}{ VARIABLES } & (1) & (2) & (3) & (4) & (5) & (6) & (7) & (8) \\
\hline & \multicolumn{4}{|c|}{$\begin{array}{l}\text { Strategy Method } \\
\text { (Round } 6 \text { to } 10 \text { ) }\end{array}$} & \multicolumn{4}{|c|}{$\begin{array}{l}\text { Strategy Method } \\
\text { (Round } 6 \text { to 10) }\end{array}$} \\
\hline & $\mathrm{T} 1$ & $\mathrm{~T} 2$ & $\mathrm{~T} 3$ & $\mathrm{~T} 4$ & $\mathrm{~T} 1$ & $\mathrm{~T} 2$ & $\mathrm{~T} 3$ & $\mathrm{~T} 4$ \\
\hline HCA dummy & $\begin{array}{c}-0.859 * * \\
(0.334)\end{array}$ & $\begin{array}{l}-0.182 \\
(0.340)\end{array}$ & $\begin{array}{l}0.467^{*} \\
(0.275)\end{array}$ & $\begin{array}{c}0.767 * * * \\
(0.278)\end{array}$ & $\begin{array}{c}-1.144 * * * \\
(0.338)\end{array}$ & $\begin{array}{c}0.035 \\
(0.342)\end{array}$ & $\begin{array}{c}0.016 \\
(0.395)\end{array}$ & $\begin{array}{l}-0.299 \\
(0.493)\end{array}$ \\
\hline Constant & $\begin{array}{c}-0.619 * * * \\
(0.222)\end{array}$ & $\begin{array}{c}-1.204^{* * *} \\
(0.180)\end{array}$ & $\begin{array}{c}-1.069 * * * \\
(0.221)\end{array}$ & $\begin{array}{c}-1.147 * * * \\
(0.227)\end{array}$ & $\begin{array}{c}-0.648^{* *} \\
(0.256)\end{array}$ & $\begin{array}{c}-1.701 * * * \\
(0.225)\end{array}$ & $\begin{array}{c}-2.138 * * * \\
(0.367)\end{array}$ & $\begin{array}{c}-2.002 * * * \\
(0.416)\end{array}$ \\
\hline Observations & 240 & 200 & 220 & 184 & 320 & 532 & 1,232 & 1,792 \\
\hline Clusters & 60.000 & 50.000 & 55.000 & 46.000 & 60.000 & 50.000 & 55.000 & 46.000 \\
\hline Wald chi2 & 6.606 & 0.287 & 2.874 & 7.585 & 11.431 & 0.011 & 0.002 & 0.366 \\
\hline Prob $>$ chi2 & 0.010 & 0.592 & 0.090 & 0.006 & 0.001 & 0.918 & 0.969 & 0.545 \\
\hline \multirow[t]{2}{*}{ Pseudo R2 } & 0.030 & 0.001 & 0.009 & 0.024 & 0.052 & 0.000 & 0.000 & 0.003 \\
\hline & \multicolumn{4}{|c|}{ First period cooperation rate } & \multicolumn{4}{|c|}{ All period cooperation rate } \\
\hline $\begin{array}{l}\text { HCA } \\
\text { participants }\end{array}$ & $\begin{array}{c}0.186 \\
(0.033)\end{array}$ & $\begin{array}{c}0.2 \\
(0.048)\end{array}$ & $\begin{array}{c}0.354 \\
(0.042)\end{array}$ & $\begin{array}{c}0.406 \\
(0.049)\end{array}$ & $\begin{array}{c}0.143 \\
(0.026)\end{array}$ & $\begin{array}{c}0.159 \\
(0.026)\end{array}$ & $\begin{array}{c}0.107 \\
(0.012)\end{array}$ & $\begin{array}{c}0.091 \\
(0.009)\end{array}$ \\
\hline
\end{tabular}




$\begin{array}{lcccccccc}\text { LCA } & 0.35 & 0.231 & 0.256 & 0.241 & 0.344 & 0.154 & 0.105 & 0.119 \\ \text { participants } & (0.048) & (0.037) & (0.046) & (0.047) & (0.042) & (0.020) & (0.136) & (0.011)\end{array}$

a: HCA dummy $=1$ for HCA participants and 0 for LCA participants. Male $=1$ for male and 0 for female.

Economics $=1$ for students from economics and management major and 0 for otherwise. ${ }^{\text {b: }}$ The unit of observation is the decision making in period 1 in every round. The total number of observations is the number of subjects $\times$ number of rounds. ${ }^{c}$ : The robust standard errors cluster by group are in parentheses. ${ }^{* * *} \mathrm{p}<0.01,{ }^{* *} \mathrm{p}$ $<0.05$, and $* \mathrm{p}<0.1$

Table A20. Odds ratio estimates of logistic regression of HCA dummy on first period cooperation and all periods cooperation in strategy method (Simulation) with robust standard error clustered by group

\begin{tabular}{|c|c|c|c|c|c|c|c|c|}
\hline \multirow[b]{4}{*}{ VARIABLES } & (1) & (2) & (3) & (4) & (5) & (6) & (7) & (8) \\
\hline & \multicolumn{4}{|c|}{$\begin{array}{c}\text { Strategy Method } \\
\text { (Simulation) }\end{array}$} & \multicolumn{4}{|c|}{$\begin{array}{l}\text { Strategy Method } \\
\text { (Simulation) }\end{array}$} \\
\hline & \multicolumn{4}{|c|}{ First period cooperation } & \multicolumn{4}{|c|}{ All period cooperation } \\
\hline & $\mathrm{T} 1$ & $\mathrm{~T} 2$ & $\mathrm{~T} 3$ & $\mathrm{~T} 4$ & $\mathrm{~T} 1$ & $\mathrm{~T} 2$ & $\mathrm{~T} 3$ & $\mathrm{~T} 4$ \\
\hline HCA dummy & $\begin{array}{c}-0.859 * * * \\
(0.015)\end{array}$ & $\begin{array}{l}-0.024 \\
(0.020)\end{array}$ & $\begin{array}{c}0.218 * * * \\
(0.012)\end{array}$ & $\begin{array}{c}0.702 * * * \\
(0.008)\end{array}$ & $\begin{array}{c}-0.807 * * * \\
(0.016)\end{array}$ & $\begin{array}{l}0.034 * \\
(0.020)\end{array}$ & $\begin{array}{c}0.125 * * * \\
(0.014)\end{array}$ & $\begin{array}{c}0.097 * * * \\
(0.010)\end{array}$ \\
\hline Constant & $\begin{array}{c}-0.619 * * * \\
(0.010)\end{array}$ & $\begin{array}{c}-1.275 * * * \\
(0.012)\end{array}$ & $\begin{array}{c}-0.463 * * * \\
(0.010)\end{array}$ & $\begin{array}{c}-0.976 * * * \\
(0.006)\end{array}$ & $\begin{array}{c}-0.735 * * * \\
(0.010)\end{array}$ & $\begin{array}{c}-1.588 * * * \\
(0.014)\end{array}$ & $\begin{array}{c}-1.377 * * * \\
(0.015)\end{array}$ & $\begin{array}{c}-1.790 * * * \\
(0.010)\end{array}$ \\
\hline Observations & 109,200 & 56,200 & 116,700 & 241,640 & 145,600 & 148,100 & 460,560 & $2,773,568$ \\
\hline Clusters & 27300 & 14050 & 29175 & 60410 & 27300 & 14050 & 29175 & 60410 \\
\hline Wald chi2 & 3326.01 & 1.38 & 322.65 & 7017.64 & 2622.39 & 2.97 & 81.90 & 88.26 \\
\hline Prob $>$ chi 2 & 0.000 & 0.240 & 0.000 & 0.000 & 0.000 & 0.085 & 0.000 & 0.000 \\
\hline \multirow[t]{2}{*}{ Pseudo R2 } & 0.030 & 0.000 & 0.002 & 0.021 & 0.026 & 0.000 & 0.001 & 0.000 \\
\hline & \multicolumn{4}{|c|}{ First period cooperation rate } & \multicolumn{4}{|c|}{ All period cooperation rate } \\
\hline $\begin{array}{l}\text { HCA } \\
\text { participants }\end{array}$ & $\begin{array}{c}0.186 \\
(0.002)\end{array}$ & $\begin{array}{c}0.214 \\
(0.003)\end{array}$ & $\begin{array}{c}0.439 \\
(0.002)\end{array}$ & $\begin{array}{c}0.432 \\
(0.001)\end{array}$ & $\begin{array}{c}0.176 \\
(0.001)\end{array}$ & $\begin{array}{c}0.174 \\
(0.002)\end{array}$ & $\begin{array}{c}0.222 \\
(0.001)\end{array}$ & $\begin{array}{c}0.155 \\
(0.000)\end{array}$ \\
\hline $\begin{array}{l}\text { LCA } \\
\text { participants }\end{array}$ & $\begin{array}{c}0.350 \\
(0.002)\end{array}$ & $\begin{array}{c}0.218 \\
(0.002)\end{array}$ & $\begin{array}{c}0.386 \\
(0.002)\end{array}$ & $\begin{array}{c}0.274 \\
(0.001)\end{array}$ & $\begin{array}{c}0.324 \\
(0.002)\end{array}$ & $\begin{array}{c}0.170 \\
(0.001)\end{array}$ & $\begin{array}{c}0.201 \\
(0.001)\end{array}$ & $\begin{array}{c}0.143 \\
(0.000)\end{array}$ \\
\hline
\end{tabular}

a: HCA dummy $=1$ for HCA participants and 0 for LCA participants. Male $=1$ for male and 0 for female.

Economics $=1$ for students from economics and management major and 0 for otherwise. ${ }^{\text {b: }}$ The unit of observation is the decision making in period 1 in every round. The total number of observations is the number of subjects $\times$ number of rounds. ${ }^{c}$ : The robust standard errors cluster by group are in parentheses. ${ }^{* * *} \mathrm{p}<0.01,{ }^{* *} \mathrm{p}$ $<0.05$, and $* \mathrm{p}<0.1$

Table A21. Odds ratio estimates of logistic regression of HCA dummy on the fully cooperative strategy in strategy method stage, with robust standard error 
HCA dummy

Constant

\begin{tabular}{lcccc} 
Observations & 240 & 200 & 220 & 184 \\
Wald chi2 & 8.384 & 3.494 & 0.002 & 3.777 \\
Prob > chi2 & 0.004 & 0.062 & 0.965 & 0.052 \\
Pseudo R2 & 0.035 & 0.026 & 0.000 & 0.019 \\
\hline \multicolumn{5}{c}{ Frequency } \\
\hline HCA participants & $0.143(0.030)$ & $0.071(0.031)$ & $0.231(0.037)$ & $0.307(0.046)$ \\
LCA participants & $0.300(0.046)$ & $0.169(0.033)$ & $0.233(0.045)$ & $0.181(0.042)$
\end{tabular}

a: HCA dummy $=1$ for HCA participants and 0 for LCA participants. Male $=1$ for male and 0 for female. Economics $=1$ for students from economics and management major and 0 for otherwise. ${ }^{\mathrm{b}}$ : The unit of observation is the elicited strategy in every round. The total number of observations is the number of subjects $x$ number of rounds. ${ }^{c}$ : The robust standard errors are in parentheses. ${ }^{* * *} \mathrm{p}<0.01, * * \mathrm{p}<0.05$, and $* \mathrm{p}<0.1$

Table A22. Odds ratio estimates of logistic regression of HCA dummy on the forgiving strategy in strategy method stage, with robust standard error

VARIABLES

HCA dummy

Constant
(1)

$\mathrm{T} 1$

$-0.206$

$(0.360)$

$-1.586^{* * * *}$

$(0.267)$

240

0.327

0.567

0.002
(2)

Forgiving strategy

\begin{tabular}{lcccc} 
Observations & 240 & 200 & 220 & 184 \\
Wald chi2 & 0.327 & 1.930 & 0.000 & 3.993 \\
Prob > chi2 & 0.567 & 0.165 & 0.987 & 0.046 \\
Pseudo R2 & 0.002 & 0.015 & 0.000 & 0.024 \\
\hline
\end{tabular}

\begin{tabular}{lllll}
\multicolumn{4}{c}{0.002} & \multicolumn{4}{c}{ Frequency } \\
\hline HCA participants & $0.143(0.030)$ & $0.071(0.031)$ & $0.177(0.034)$ & $0.238(0.043)$ \\
LCA participants & $0.170(0.038)$ & $0.138(0.030)$ & $0.178(0.041)$ & $0.120(0.036)$
\end{tabular}

a: HCA dummy $=1$ for HCA participants and 0 for LCA participants. Male $=1$ for male and 0 for female. 
Economics $=1$ for students from economics and management major and 0 for otherwise. ${ }^{\mathrm{b}}$ : The unit of observation is the elicited strategy in every round. The total number of observations is the number of subjects $x$ number of rounds. ${ }^{c}$ : The robust standard errors are in parentheses. ${ }^{* * *} \mathrm{p}<0.01,{ }^{* *} \mathrm{p}<0.05$, and $* \mathrm{p}<0.1$

Table A23. Odds ratio estimates of logistic regression of HCA dummy on the lenient strategy in strategy method stage, with robust standard error

(1)

$\mathrm{T} 1$

VARIABLES

HCA dummy

Constant $\mathrm{T} 1$
(2)

\section{Lenient strategy}

$\mathrm{T} 2$

$-0.671$

(0.533)

(0.364)

$-1.586^{* * * *}$

(0.267)

$-1.894 * * *$

(0.261)

(3)

$\mathrm{T} 3$

$-0.080$

0.767*

(0.355)

(0.399)

$-1.457 * * *$

(0.270)$$
(0.325)
$$

(0.325)

184

3.703

0.054

0.022

\begin{tabular}{lcccc} 
Observations & 240 & 200 & 220 & 184 \\
Wald chi2 & 0.534 & 1.582 & 0.051 & 3.703 \\
Prob > chi2 & 0.465 & 0.209 & 0.821 & 0.054 \\
Pseudo R2 & 0.003 & 0.013 & 0.000 & 0.022 \\
\hline
\end{tabular}

\begin{tabular}{lllll}
\hline & \multicolumn{5}{c}{ Frequency } \\
\hline HCA participants & $0.136(0.029)$ & $0.071(0.031)$ & $0.177(0.034)$ & $0.248(0.043)$ \\
LCA participants & $0.170(0.038)$ & $0.131(0.030)$ & $0.189(0.041)$ & $0.133(0.037)$
\end{tabular}

a: HCA dummy $=1$ for HCA participants and 0 for LCA participants. Male $=1$ for male and 0 for female.

Economics $=1$ for students from economics and management major and 0 for otherwise. ${ }^{\text {b}}$ : The unit of observation is the elicited strategy in every round. The total number of observations is the number of subjects $x$ number of rounds. ${ }^{c}$ : The robust standard errors are in parentheses. $* * * p<0.01, * * p<0.05$, and $* p<0.1$ 


\section{F. The frequency of unconditional defection strategy between HCA participants and LCA participants}

Table A24. Odds ratio estimates of logistic regression of HCA dummy and demographic characteristics on the unconditional strategy in strategy method stage, with robust standard error
(1)
(2)
(3)
(4)

Unconditional defection

\section{VARIABLES}

$\mathrm{T} 1$

$\mathrm{T} 2$

$\mathrm{T} 3$

$\mathrm{T} 4$

\begin{tabular}{|c|c|c|c|c|}
\hline HCA dummy & $\begin{array}{c}0.376 \\
(0.277)\end{array}$ & $\begin{array}{l}1.006^{* *} \\
(0.402)\end{array}$ & $\begin{array}{l}-0.0791 \\
(0.288)\end{array}$ & $\begin{array}{c}-0.834 * * \\
(0.324)\end{array}$ \\
\hline Age & $\begin{array}{l}-0.012 \\
(0.089)\end{array}$ & $\begin{array}{c}0.011 \\
(0.149)\end{array}$ & $\begin{array}{l}-0.029 \\
(0.071)\end{array}$ & $\begin{array}{c}0.064 \\
(0.088)\end{array}$ \\
\hline Male & $\begin{array}{l}-0.109 \\
(0.293)\end{array}$ & $\begin{array}{c}-1.161 * * * \\
(0.380)\end{array}$ & $\begin{array}{l}-0.158 \\
(0.300)\end{array}$ & $\begin{array}{l}-0.380 \\
(0.316)\end{array}$ \\
\hline Economics & $\begin{array}{c}1.642 * * * \\
(0.550)\end{array}$ & $\begin{array}{c}0.851 * * \\
(0.342)\end{array}$ & $\begin{array}{c}0.272 \\
(0.374)\end{array}$ & $\begin{array}{c}0.452 \\
(0.330)\end{array}$ \\
\hline Constant & $\begin{array}{l}-0.392 \\
(1.866)\end{array}$ & $\begin{array}{l}-0.725 \\
(2.985)\end{array}$ & $\begin{array}{c}0.595 \\
(1.538)\end{array}$ & $\begin{array}{l}-1.210 \\
(1.772)\end{array}$ \\
\hline Observations & 240 & 200 & 220 & 184 \\
\hline Wald chi2 & 12.83 & 14.34 & 1.952 & 9.100 \\
\hline Prob > chi2 & 0.012 & 0.006 & 0.745 & 0.059 \\
\hline Pseudo R2 & 0.038 & 0.063 & 0.007 & 0.037 \\
\hline & \multicolumn{4}{|c|}{ Predicted Frequency } \\
\hline HCA participants & $0.448(0.040)$ & $0.553(0.066)$ & $0.469(0.045)$ & 0.305 (0.046) \\
\hline LCA participants & $0.362(0.048)$ & $0.335(0.038)$ & $0.489(0.054)$ & $0.498(0.054)$ \\
\hline
\end{tabular}

a: HCA dummy $=1$ for HCA participants and 0 for LCA participants. Male $=1$ for male and 0 for female. Economics $=1$ for students from economics and management major and 0 for otherwise. ${ }^{\text {b: }}$ : The unit of observation is the elicited strategy in every round. The total number of observations is the number of subjects $x$ number of rounds. ${ }^{c}$ : The robust standard errors are in parentheses. $* * * p<0.01, * * p<0.05$, and $* \mathrm{p}<0.1$

Table A25. Odds ratio estimates of logistic regression of HCA dummy on the unconditional defection strategy in strategy method stage, with robust standard error
(1)
(2)
(3)
(4)

Unconditional defection

VARIABLES

$\mathrm{T} 1$

$\mathrm{T} 2$

$\mathrm{T} 3$

$\mathrm{T} 4$

HCA dummy

$$
0.303
$$

0.240

$-0.154$

$-0.696 * *$

Constant

$(0.269)$

(0.301)

(0.275)

(0.307)

$-0.532 * *$

$-0.470 * * *$

$-0$

$-0.0723$

$(0.208)$

(0.181)

$(0.211)$

$(0.220)$ 


\begin{tabular}{lcccc} 
Observations & 240 & 200 & 220 & 184 \\
Wald chi2 & 1.269 & 0.636 & 0.314 & 5.126 \\
Prob > chi2 & 0.260 & 0.425 & 0.575 & 0.0236 \\
Pseudo R2 & 0.00394 & 0.00236 & 0.00104 & 0.0212 \\
\hline \multicolumn{5}{c}{ Frequency } \\
\hline HCA participants & $0.443(0.042)$ & $0.443(0.060)$ & $0.462(0.044)$ & $0.317(0.046)$ \\
LCA participants & $0.37(0.048)$ & $0.385(0.043)$ & $0.5(0.053)$ & $0.482(0.055)$ \\
& & & &
\end{tabular}

a: HCA dummy $=1$ for HCA participants and 0 for LCA participants. Male $=1$ for male and 0 for female. Economics $=1$ for students from economics and management major and 0 for otherwise. ${ }^{b}$ : The unit of observation is the elicited strategy in every round. The total number of observations is the number of subjects $x$ number of rounds. ${ }^{c}$ : The robust standard errors are in parentheses. ${ }^{* *} \mathrm{p}<0.01, * * \mathrm{p}<0.05$, and ${ }^{*} \mathrm{p}<0.1$ 


\section{G. Average payoff between HCA participants and LCA participants}

Table A26. OLS regression of HCA dummy and demographic characteristics on payoff in direct response method (Round 1 to 5), strategy method (Round 6 to 10) and strategy method (simulation) with robust standard error clustered by group

\begin{tabular}{|c|c|c|c|c|c|c|c|c|c|c|c|c|}
\hline \multirow[b]{4}{*}{ VARIABLES } & (1) & (2) & (3) & (4) & (5) & (6) & (7) & (8) & (9) & (10) & (11) & (12) \\
\hline & \multirow{2}{*}{\multicolumn{4}{|c|}{$\begin{array}{c}\text { Direct Response Method } \\
\text { (Round } 1 \text { to 5) } \\
\text { Payoff }\end{array}$}} & \multirow{2}{*}{\multicolumn{4}{|c|}{$\begin{array}{l}\text { Strategy Method } \\
\text { (Round } 6 \text { to 10) } \\
\text { Payoff }\end{array}$}} & \multirow{2}{*}{\multicolumn{4}{|c|}{$\begin{array}{l}\text { Strategy Method } \\
\text { (Simulation) } \\
\text { Payoff }\end{array}$}} \\
\hline & & & & & & & & & & & & \\
\hline & T1 & $\mathrm{T} 2$ & T3 & $\mathrm{T} 4$ & $\mathrm{~T} 1$ & $\mathrm{~T} 2$ & T3 & T4 & T1 & $\mathrm{T} 2$ & T3 & $\mathrm{T} 4$ \\
\hline HCA dummy & $\begin{array}{c}0.783 \\
(0.514)\end{array}$ & $\begin{array}{l}1.431 * * \\
(0.558)\end{array}$ & $\begin{array}{l}-0.057 \\
(0.481)\end{array}$ & $\begin{array}{l}-0.811^{*} \\
(0.460)\end{array}$ & $\begin{array}{c}0.447 \\
(0.506)\end{array}$ & $\begin{array}{l}-0.253 \\
(0.663)\end{array}$ & $\begin{array}{c}0.255 \\
(0.332)\end{array}$ & $\begin{array}{l}-0.219 \\
(0.363)\end{array}$ & $\begin{array}{c}0.930^{* * * *} \\
(0.027)\end{array}$ & $\begin{array}{l}0.074 * \\
(0.041)\end{array}$ & $\begin{array}{c}0.289 * * * \\
(0.022)\end{array}$ & $\begin{array}{c}0.153^{* * * *} \\
(0.014)\end{array}$ \\
\hline Age & $\begin{array}{c}0.227 \\
(0.170)\end{array}$ & $\begin{array}{l}-0.272 \\
(0.208)\end{array}$ & $\begin{array}{l}0.214 * \\
(0.111)\end{array}$ & $\begin{array}{l}-0.220^{*} \\
(0.127)\end{array}$ & $\begin{array}{l}-0.246^{*} \\
(0.132)\end{array}$ & $\begin{array}{l}-0.069 \\
(0.177)\end{array}$ & $\begin{array}{c}0.231 * * \\
(0.106)\end{array}$ & $\begin{array}{l}-0.065 \\
(0.164)\end{array}$ & $\begin{array}{c}0.081^{* * * *} \\
(0.007)\end{array}$ & $\begin{array}{c}-0.091 * * * \\
(0.011)\end{array}$ & $\begin{array}{c}0.153 * * * \\
(0.006)\end{array}$ & $\begin{array}{l}-0.008 \\
(0.005)\end{array}$ \\
\hline \multirow[t]{2}{*}{ Male } & -0.232 & $-1.245^{* *}$ & -0.271 & 0.119 & -0.089 & -0.409 & 0.561 & 0.362 & $-0.375^{* * *}$ & $-0.309 * * *$ & $\begin{array}{c}- \\
0.154 * * *\end{array}$ & $0.077 * * *$ \\
\hline & $(0.403)$ & $(0.523)$ & $(0.416)$ & $(0.487)$ & $(0.557)$ & $(0.524)$ & $(0.432)$ & $(0.364)$ & $(0.027)$ & $(0.039)$ & $(0.022)$ & $(0.014)$ \\
\hline Economics & $\begin{array}{c}0.102 \\
(0.607)\end{array}$ & $\begin{array}{l}1.452^{* * *} \\
(0.555)\end{array}$ & $\begin{array}{l}-0.107 \\
(0.452)\end{array}$ & $\begin{array}{l}-0.196 \\
(0.471)\end{array}$ & $\begin{array}{c}0.997 \\
(1.056)\end{array}$ & $\begin{array}{c}0.481 \\
(0.411)\end{array}$ & $\begin{array}{c}0.206 \\
(0.531)\end{array}$ & $\begin{array}{c}0.376 \\
(0.363)\end{array}$ & $\begin{array}{c}1.389^{* * * *} \\
(0.044)\end{array}$ & $\begin{array}{c}0.586 * * * \\
(0.033)\end{array}$ & $\begin{array}{c}0.358 * * * \\
(0.031)\end{array}$ & $\begin{array}{c}0.137 * * * \\
(0.016)\end{array}$ \\
\hline Constant & $\begin{array}{c}7.817 * * \\
(3.608)\end{array}$ & $\begin{array}{c}17.779 * * * \\
(4.204)\end{array}$ & $\begin{array}{c}8.628 * * * \\
(2.468)\end{array}$ & $\begin{array}{c}17.198 * * * \\
(2.784)\end{array}$ & $\begin{array}{c}17.112^{* * * *} \\
(2.808)\end{array}$ & $\begin{array}{c}13.087 * * * \\
(3.545)\end{array}$ & $\begin{array}{c}5.837^{* *} \\
(2.225)\end{array}$ & $\begin{array}{c}12.113 * * * \\
(3.263)\end{array}$ & $\begin{array}{c}10.194 * * * \\
(0.155)\end{array}$ & $\begin{array}{c}13.527 * * * \\
(0.224)\end{array}$ & $\begin{array}{c}8.758 * * * \\
(0.136)\end{array}$ & $\begin{array}{c}11.482^{* * * *} \\
(0.106)\end{array}$ \\
\hline Observations & 400 & 464 & 1,256 & 1,776 & 320 & 532 & 1,232 & 1,792 & 145,600 & 148,100 & 460,560 & $2,773,568$ \\
\hline Clusters & 60 & 50 & 55 & 50 & 60 & 50.000 & 55 & 46 & 27300 & 14050 & 29175 & 60410 \\
\hline $\mathrm{F}$ & 0.958 & 4.113 & 1.821 & 1.476 & 1.741 & 1.109 & 2.253 & 0.657 & 491.00 & 131.15 & 192.49 & 59.24 \\
\hline Prob $>$ F & 0.437 & 0.006 & 0.138 & 0.224 & 0.153 & 0.363 & 0.075 & 0.625 & 0.000 & 0.000 & 0.000 & 0.000 \\
\hline \multirow[t]{2}{*}{$\mathrm{R} 2$} & 0.013 & 0.042 & 0.009 & 0.019 & 0.018 & 0.011 & 0.027 & 0.008 & 0.019 & 0.007 & 0.006 & 0.001 \\
\hline & \multicolumn{4}{|c|}{ Predicted average payoff } & \multicolumn{4}{|c|}{ Predicted average payoff } & \multicolumn{4}{|c|}{ Predicted average payoff } \\
\hline
\end{tabular}




\begin{tabular}{|c|c|c|c|c|c|c|c|c|c|c|c|c|}
\hline $\mathrm{HCA}$ & 13.254 & 13.675 & 12.820 & 11.978 & 12.433 & 11.400 & 11.169 & 10.938 & 12.747 & 11.761 & 12.251 & 11.567 \\
\hline participants & $(0.366)$ & $(0.531)$ & $(0.374)$ & $(0.370)$ & $(0.430)$ & $(0.512)$ & $(0.269)$ & $(0.304)$ & $(0.019)$ & $(0.031)$ & $(0.017)$ & $(0.013)$ \\
\hline LCA & 12.471 & 12.244 & 12.876 & 12.789 & 11.986 & 11.653 & 10.915 & 11.157 & 11.817 & 11.687 & 11.962 & 11.414 \\
\hline participants & $(0.366)$ & $(0.325)$ & $(0.395)$ & $(0.460)$ & $(0.366)$ & $(0.283)$ & $(0.255)$ & $(0.309)$ & $(0.020)$ & $(0.022)$ & $(0.022)$ & $(0.013)$ \\
\hline
\end{tabular}

a: HCA dummy = 1 for HCA participants and 0 for LCA participants. Male $=1$ for male and 0 for female. Economics =1 for students from economics and management major and 0 for otherwise. ${ }^{b}$ : The unit of observation is the decision making in all periods in every round. The total number of observations is the number of subjects $\times$ number of rounds $\times$ number of periods. ${ }^{c}$ : The robust standard errors cluster by group are in parentheses. $* * * p<0.01, * * \mathrm{p}<0.05$, and $* \mathrm{p}<$ 0.1 


\section{H. Experimental instruction}

\section{Sample of Experimental Instruction for treatment 4 (in Japanese)}

\section{経済実験説明書}

実験にご参加いただきありがとうございます。これから、経済実験を行います。説明書をよく読 み、内容を完全に理解して参加ください。何か不明な点があれば、すぐに手を上げスタッフにお知 らせください。

\section{1. 配布資料}

席に着いたら、A4 用紙の紙が 5 種類あることを確認して下さい。
1. 実験参加同意書
2. 実験説明書
3. 画面説明書
4. 記録用紙
5. 領収書

\section{2. 実験の報酬について}

実験の報酬は 2 つの部分からなります。1つは参加報酬です。参加報酬として皆様全員に 1000 円 をお支払いします。もう１つは成果報酬です。成果報酬は実験の結果によって決まります。

3. グループの決まり方

> ゲーム開始時に、グループがランダムに決まります。全てのグル 一プは 4 人の参加者からなります。グループ番号がコンピュータ 画面に表示されます。

> 各ラウンドで、グループは同じです。あなたは、グループのメン バーが誰なのかを知ることはできません。

実験は 10 ラウンドからなります。この実験は、前半 5 ラウンド と後半 5 ラウンドで意思決定の仕方が異なりますが、グループの 決まり方とピリオドの決まり方は同じです。

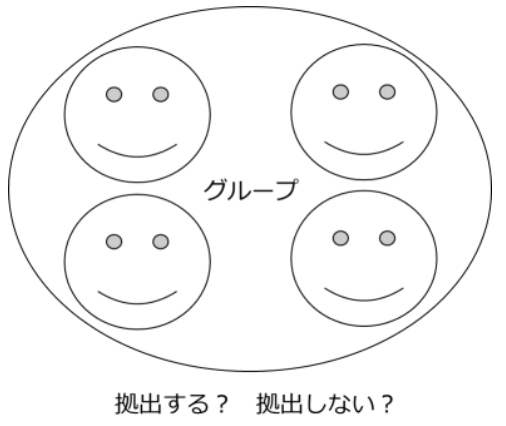

> 各ラウンドの開始時点で、全てのグループはランダムに組みなおされます。従って、あなたはも う一度同じメンバーとグループを組むかもしれませんし、まったく新しいメンバーとグループ を組むかもしれません。

> グループ番号を確認したら、次の意思決定に進んでください。

\section{4. 各ラウンドでのピリオドの決まり方}

実験は 10 ラウンドからなります。

> 各ラウンドが何ピリオド続くのかは、実験者がくじで決めます。

> 実験者は各ピリオド終了時に、10枚のカードから 1 枚を引きます。

> 10 枚のカードは、スペード（）が 9 枚、ジョーカーが 1 枚です。

> ピリオド終了時に、実験者がこの 10 枚のカードから 1 枚をランダムに引きます。

> 実験者が引いたカードが、スペード（の）だった場合、次のピリオドに進みます。

> 実験者がジョーカーを引いた場合、ピリオドは終了し、次のラウンドに進みます。

> 従って、各ピリオドは 90\%(=9/10)で続き、10\%(=1/10)で終了します。 


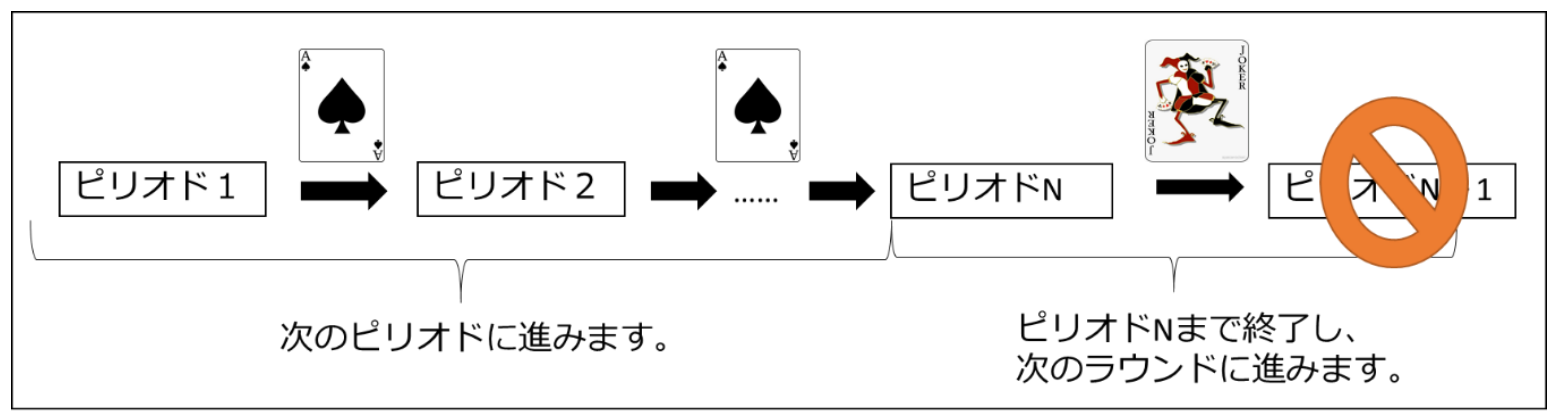

\section{5-1. 意思決定（前半パート）}

はじめに、1〜 5ラウンドの前半パートでの意思決定を説明します。

各参加者は、各ピリオドのはじめに初期保有ポイントとして 10 ポイントを与えられます。10 ポイ ントから、グループの公共財に全額拠出するまたは拠出しないから選んで下さい。

\section{5-2. 意思決定（後半パート）}

次に、6〜10 ラウンドの後半ラウンドでの意思決定について説明します。後半ラウンドのはじめ に、各ラウンドにおける意思決定の方針を定めます。後半ラウンドでは、あなたの定めた行動方 針によって、公共財に全額拠出するまたは拠出しないが決定されます。

> 具体的には、9問の質問に回答することで、あなたの行動方針が定まります。各設問は、 (1)第 1 ピリオドで公共財に全額拠出するか否か（全 1 問）、

(2)1 期前にあなたの選択（拠出する、拠出しない）及びグループの拠出額 (0，10，20，30、40) に応じて、今期あなたは公共財に拠出するか否か（全 8 問）です。

> 各設問はランダムな順番で画面に表示されます。全てに回答して下さい。

> 全ての質問（合計 9 問）の回答が終わると、あなたの選んだ方針を確認する画面が表示されま す。自分の選んだ方針を記録用紙にメモしてください。

> 後半ラウンドでは、行動方針が定まった後は、その方針に基づいて自動的にゲームがプレイさ れ、あなたは各ピリオドで結果を確認するだけです。

> 各ラウンドのはじめに、同じ 9 の質問が表示されます。過去のラウンドと同じ方針を採用する 場合、記録用紙を見ながら前のラウンドと同じ回答を入力してください。

\section{6. 利得の決まり方}

あなたはグループの総拠出額を知ることができます。

あなたのポイントは、グループの総拠出額によって決まります。あるピリオドのあなたの利得は 以下の式で計算されます。

\section{あるピリオドにおけるあなたのポイント \\ $=10$ 一自分の拠出額 $+0.5 \times(ク ゙ ル ー フ ゚ の$ 総拠出額 $)$}

例えば、あなたが 10 ポイントを全額拠出し、グループの総拠出額が 40 ポイントの場合を考えまし ょう。このピリオドのあなたの利得は以下のようになります。

このピリオドのあなたのポイント $=(10-10)+0.5 \times 40=0+20=20$ 
例えば、あなたが拠出しない、グループの総拠出額が 0 ポイントの場合を考えましょう。このピリ オドのあなたの利得は以下のようになります。

このピリオドのあなたのポイント $=(10-0)+0.5 \times 0=10+0=10$

\section{7. 報酬額}

あなたの最終ポイントは、10 ラウンドの合計ポイントで計算されます。 1 ポイント= 3 円で計算され、 参加報酬 1000 円と合計してあなたへの報酬額が決定されます。

あなたの報酬額

$=¥ 1000+10$ ラウンドの合計ポイントメ $¥ 3$ 


\section{Economic Experiment Instructions}

Thank you for participating in our experiment. We will conduct an economic experiment. Please read the instructions carefully and make sure you understand the content fully. If you have any questions, please raise your hand immediately and let the staff know.

\section{Handouts}

When you get to your seat, make sure you have five handouts:

1. Experiment Participation Agreement 2. Experiment Instructions 3. Screen Instructions 4. Record Form 5. Receipt

\section{How to decide the profit}

The profit for the participants consists of two parts. The first is the participation payment. We will pay JPY 1,000 to all of you for your participation. The second is the experiment payment. The result of the experiment determines the amount to be paid.

\section{How to set up a group}

$>$ At the start of the game, the group is randomly determined. All groups consist of four participants. Your group number appears on the computer screen.

$>$ For each round, the group is the same. You won't know who the other group members are.

$>$ The experiment consists of $\mathbf{1 0}$ rounds. This experiment is different in the first five rounds and the last five rounds, but the way groups are formed is

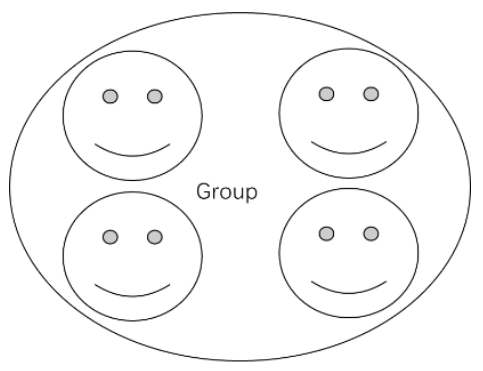

Contribute? Not contribute? the same.

$>$ At the beginning of each round, all groups are randomly regrouped. Therefore, you may join the same members again, or you may go with entirely new members.

$>$ Once you have verified the group number, proceed to the next decision.

\section{How to set the number of periods in each round}

The experiment consists of 10 rounds.

$>$ The experimenter decides how many periods each round lasts.

$>$ At the end of each period, the experimenter draws one from ten cards.

$>$ There are nine spades $(\boldsymbol{\$})$ and one Joker.

$>$ At the end of the period, the experimenter randomly draws one of these ten cards.

$>$ If the card drawn by the experimenter was a spade (\$), go to the next period.

$>$ If the card drawn by the experimenter was a Joker, the period ends and proceeds to the next round. 
Therefore, each period is followed by $90 \%(=9 / 10)$ and ends at $10 \%(=1 / 10)$.

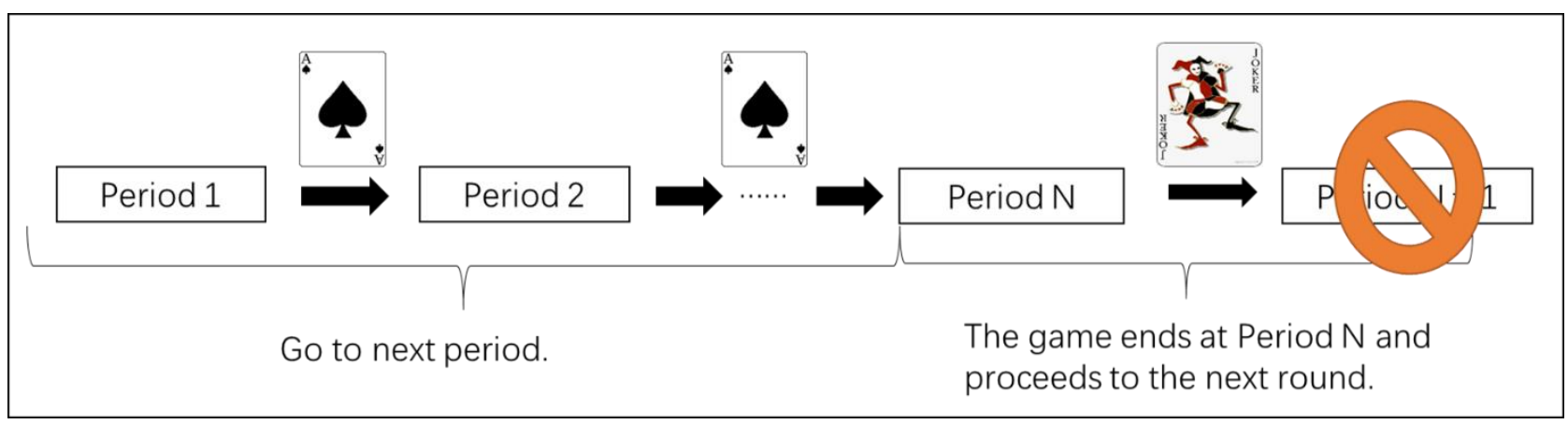

\section{5-1. Decision making (First Five Rounds)}

First, let's consider the decision making from Round 1 to Round 5. Each participant is given 10 points as the initial endowment at the beginning of each period. Please choose from 10 points to fully contribute or not contribute to the group's public goods.

\section{5-2. Decision-Making (Last Five Rounds)}

Next, we'll talk about the decision-making from Round 6 to Round 10. At the beginning of each round, you will be asked to create a strategic plan. Your strategic plan will determine whether you will fully contribute or not contribute to public goods.

$>$ Specifically, you will be asked to answer the following nine questions to frame your strategic plan:

(1) Will you contribute fully to public goods in the first period? (There is a total of 1 question.).

(2) Depending on your choice (contribution, no contribution) and the group's contribution $(0,10,20,30$,

40 ) in the previous period, will you contribute fully to public goods in this current period? (There is a total of 8 questions.).

$>$ Each question is displayed on the screen in random order. Please answer all questions.

$>$ After answering all of the questions ( 9 questions in total), you will be prompted to review your chosen strategic plan. Make a note of your choice on the record form.

$>$ Once you decide upon your strategic plan, the game is automatically played, based on that strategic plan, and you only need to read the results for each period.

$>$ At the beginning of each round, you'll see the same nine questions. If you want to adopt the same strategy as in the past rounds, check the record form and enter the same choice as the previous round.

\section{How to determine the gain}

You can know the total contribution of your group. Your points are determined by the total contribution of your group. The following equation calculates your point for a period:

\section{Your point in a period}

$=10-$ My contribution $+0.5 \times($ total contribution of the group $)$

For example, consider a case where you fully contribute, and your group contributes 40 points in total. Your profit in this period:

Your point of this period $=(10-10)+0.5 \times 40=0+20=20$ 
Consider a case when you do not contribute, and your group contributes 0 points in total. Your profit in this period:

Your point of this period $=(10-0)+0.5 \times 0=10+0=10$

\section{Total Profit}

Your final point is calculated at an overall point of 10 rounds. It is calculated at 1 point $=$ JPY 3 , and your total profit amount is determined with the participation fee of JPY 1000.

Your total profit $=$ JPY $1000+$ total points in 10 rounds $\times$ JPY 3

\section{References}

Carlsson, H., \& Van Damme, E. (1993). Equilibrium Selection in Stag Hunt Games. Frontiers of game theory, 237.

Dal Bó, P., \& Fréchette, G. R. (2011). The evolution of cooperation in infinitely repeated games:

Experimental evidence. American Economic Review, 101(1), 411-29.

Fudenberg, D., Rand, D.G., Dreber, A. (2012). Slow to anger and fast to forgive: Cooperation in an uncertain world. American Economic Review, 102 (2), 720-49.

Harsanyi, J. C., \& Selten, R. (1988). A general theory of equilibrium selection in games. MIT Press Books, 1. Kim, Y. (1996). Equilibrium selection inn-person coordination games. Games and Economic Behavior, 15 (2), 203-227. 